\title{
Die Geschichte der Soziologie im Spiegel der Kölner Zeitschrift für Soziologie und Sozialpsychologie (KZfSS)
}

\author{
Stephan Moebius
}

(C) Der/die Autor(en) 2017. Dieser Artikel ist eine Open-Access-Publikation.

Zusammenfassung Die Kölner Zeitschrift für Soziologie und Sozialpsychologie (KZfSS) gehört seit ihrer Gründung im deutschsprachigen Raum zu den zentralen Fachzeitschriften der Soziologie. Zahlreiche Beiträge der KZfSS prägten die Debatten, Kontroversen und Verlaufsprozesse der Soziologie in Deutschland oder spiegelten zentrale Fachdiskussionen und gesellschaftliche Entwicklungen wider. Ausgehend von ausgewählten Aufsätzen aus der KZfSS werden zentrale Stationen der Geschichte der Soziologie in Deutschland belichtet und nach dem Wandel soziologischer Kritik gefragt.

Schlüsselwörter Kölner Zeitschrift für Soziologie und Sozialpsychologie · Soziologiegeschichte · Geschichte der Soziologie Deutschlands · Bundesrepublikanische Soziologie · Intellektuelle · Gesellschaftskritik

\section{The History of Sociology in the light of the Kölner Zeitschrift für} Soziologie und Sozialpsychologie (KZfSS, Cologne Journal for Sociology and Social Psychology)

Abstract Ever since its foundation the Kölner Zeitschrift für Soziologie und Sozialpsychologie (KZfSS) has belonged to the seminal sociological journals in the German speaking countries. Numerous contributions to the KZfSS had a significant impact on debates, controversies, and the course of German sociology or reflected fundamental disciplinary debates and social developments. Based on selected arti-

Seitenzahlen in kursiv beziehen sich, abweichend von den Originalseitenzahlen, auf die in diesem Sonderheft wieder abgedruckten Beiträge.

S. Moebius $(\bowtie)$

Institut für Soziologie, Karl-Franzens-Universität Graz

Universitätsstraße 15/G4, 8010 Graz, Österreich

E-Mail: stephan.moebius@uni-graz.at 
cles from the KZfSS the crucial points of the sociology in Germany will be discussed and looks will be given into the changes of social criticism.

Keywords Kölner Zeitschrift für Soziologie und Sozialpsychologie · History of sociology · History of sociology in Germany · Sociology in the Federal Republic of Germany · Intellectuals · Social criticism

\section{Einleitung}

Die Kölner Zeitschrift für Soziologie und Sozialpsychologie gehört unbestritten zu den führenden Zeitschriften der deutschsprachigen Soziologie (vgl. den Beitrag Rauhut und Winter in diesem Sonderheft). Sie war zunächst unter dem Titel Kölner Vierteljahrshefte für Sozialwissenschaften. Reihe A: Soziologische Hefte nicht nur die erste, explizit unter dem Banner der Soziologie firmierende Fachzeitschrift in Deutschland (Stölting 1986, S. 168), auch erhielten Beiträge in der KZfSS bis dato die meisten Auszeichnungen des Fritz Thyssen-Preises für sozialwissenschaftliche Aufsätze (vgl. Dreier 2016, S. 2). ${ }^{1}$ Wie die Zitationsanalysen von Heiko Rauhut und Fabian Winter in diesem Sonderheft zeigen, erfährt die KZfSS international und national eine breite Wahrnehmung. Im Rahmen der Soziologie im deutschsprachigen Raum gehört sie zu den meist rezipierten Soziologiezeitschriften.

Angesichts der Bedeutung der KZfSS für die deutschsprachige Soziologie scheint ein Rückblick auf die vergangenen, nahezu hundert Jahre ihres Bestehens naheliegend. Deshalb widmet sich das vorliegende Sonderheft einer soziologiehistorischen Reflexion zentraler, ausgewählter Aufsätze. Die Auswahl der Aufsätze entspringt einem Diskussionsprozess zwischen Herausgeber- und Beiratsteam. Diese sind sich bewusst darüber, dass bei der Fülle in Frage kommender Beiträge nicht alle, die es verdient hätten, in das Sonderheft aufgenommen werden konnten, dass dieses also nicht die gesamte Geschichte der bundesrepublikanischen Soziologie repräsentieren kann.

Das vorliegende Sonderheft fügt sich in eine Reihe soziologiehistorischer Aktivitäten ein, wie sie seit einigen Jahren im deutschsprachigen Raum vermehrt zu beobachten sind. Für das zunehmende Interesse an soziologiegeschichtlicher Forschung und Reflexion sprechen beispielsweise auf institutioneller und publizistischer Ebene nicht nur Neugründungen von disziplingeschichtlich ausgerichteten Publikationsorganen wie etwa Zyklos. Jahrbuch für Theorie und Geschichte der Soziologie

\footnotetext{
1 Zur Vertiefung der Geschichte der KZfSS sei auf Volker Dreiers Aufsatz im vorliegenden Sonderheft verwiesen. Wie Leopold von Wiese im ersten Beitrag dieses Sonderhefts anführt, gab es im deutschsprachigen Raum eine Vorläuferin in der von dem Schweizer Soziologen Abroteles Eleutheropulos und Baron Alexis von Engelhardt 1909 herausgegebenen Monatsschrift für Soziologie, die aber bereits nach ihrem ersten Jahrgang eingestellt wurde. Zu deren Autoren zählten aber immerhin prominente Fachvertreter wie Ludwig Gumplowicz, Robert Michels, Franz Oppenheimer, Ferdinand Tönnies, René Worms, Alfred Vierkandt, Lester F. Ward und Achille Loria (vgl. Stölting 1986, S. 166; Zürcher 2016, S. 9). Ebenfalls zu erwähnen ist Paul Barths Vierteljahresschrift für wissenschaftliche Philosophie und Soziologie (so deren Titel seit 1902, vgl. Stölting 1986, S. 165).
} 
oder die Zeitschrift serendipities ${ }^{2}$, das zweibändige Handbuch zur Geschichte der deutschsprachigen Soziologie (Moebius und Ploder 2017), das seit 2016 online zugänglich ist und 2017 in Buchform erscheinen wird oder Soziologiegeschichte. Wege und Ziele (Dayé und Moebius 2015), in dem unterschiedliche Methodologien und Begründungen für soziologiehistorische Forschung behandelt werden. Darüber hinaus finden sich auch seit geraumer Zeit generations- und nationenübergreifend Sozialwissenschaftlerinnen und Sozialwissenschaftler zu einem regelmäßigen Austausch zusammen. ${ }^{3}$ Es wird mit Lothar Peter (2001a, S. 11; vgl. dazu Moebius 2004, 2016a) begrifflich zwischen „Soziologiegeschichte“ und „Geschichte der Soziologie“ differenziert. „Soziologiegeschichte“ meint eine eigenständige soziologische Forschungsrichtung, die sich mit der Geschichte der Soziologie, verstanden als dem ,historischen Realverlauf soziologischer Theoriebildung, Forschung und Institutionalisierung sowie aller anderen Aktivitäten und Erscheinungen, die sich auf das Verhältnis von Soziologie und Gesellschaft beziehen“, beschäftigt (Peter 2001a, S. 11). „Geschichte der Soziologie“ ist also der Untersuchungsgegenstand der Forschungsrichtung Soziologiegeschichte (vgl. Moebius 2004, S. 15 f.), die ,den geschichtlichen Prozeß der Soziologie, ihrer Akteure, Praxisformen, wissenschaftlichen Ergebnisse, Institutionen und gesellschaftlichen Funktionen“" untersucht (Peter 2001a, S. 11).

Bedeutsam ist soziologiehistorische Forschung aus mehreren Gründen (vgl. Dayé und Moebius 2015), von denen die Frage nach der Festigung einer fachdisziplinären Identität, wie sie Wolf Lepenies (1981) in seiner Einleitung zur mehrbändigen Geschichte der Soziologie dargelegt hat, nur einer ist. Andere Gründe, die für die Soziologiegeschichte als elementaren Bestandteil der Soziologie sprechen, liegen in der Vermittlung von Geschichtsbewusstsein und historischen Sichtweisen auf das Soziale sowie im Aufweis der historischen Situiertheit sozialer Phänomene, der aufgrund zunehmender Prominenz ahistorischer Ansätze, man denke an manche Spielarten der RC-Theorien oder postmoderne Verkündigungen des Endes der Geschichte, immer mehr erforderlich erscheint (vgl. Peter 2001a, S. 10). Insbesondere sind es aber zwei weitere Gründe, die meines Erachtens eine soziologiehistorische Perspektive notwendig machen. Erstens ist es ein strukturell in den Gegenständen der Soziologie angelegter Bezug auf die Geschichte:

„Insofern Sinnsetzungen stets durch vergangene Sinnsetzungen und Sinnentwürfe vorkonstituiert sind, sie mit diesen aber prinzipiell aufgrund der zeitlichen Differenz zwischen Konstruktion und Rekonstruktion nicht identisch sein können, ist Soziologie immer auf eine Differenz von Sinnsetzungen ihres Entwurfs ex ante und ihrer Erhebung ex post - verwiesen. Diese Differenz reflexiv zu thematisieren, macht das disziplinäre Profil der Soziologie

\footnotetext{
2 http://serendipities.uni-graz.at/index.php/serendipities.

3 Man denke etwa an die in Graz ausgerichteten jährlichen Spring Schools des Doktoratsprogramms Soziologie und Geschichte der Sozial- und Kulturwissenschaften (http://doktoratsprogramm-geschichtesoziologie-sozialwissenschaften.uni-graz.at/de/spring-schools) sowie die seit 2014 stattfindenden Workshops zur Geschichte der deutschsprachigen Soziologie (2014 in Graz, 2015 in Frankfurt a.M., 2016 in Konstanz).
} 
aus. Soziologie ist aufgrund ihres konstitutiven Bezogen seins auf Vergangenes strukturell auf Selbstthematisierung hin angelegt [...]“" (Endreß 2001, S. 65).

Zweitens ist Soziologiegeschichte als Reflexionsgeschichte der Beobachtung von Gesellschaft notwendig, das heißt als „Beobachtung zweiter Ordnung“, wie insbesondere Paul Nolte (2000, S. 19 ff. und S. 244 ff.) in seiner Geschichte der deutschen Soziologie festgehalten hat. Von welchen Deutungs-, Wahrnehmungs- und Ordnungsmustern ließen sich die professionellen Beobachter der Gesellschaft, die Soziologinnen und Soziologen, leiten? Was beeinflusste, förderte oder behinderte ihr Verständnis von gesellschaftlichen Prozessen? Welche „Gesellschaft“ konstruierten sie dadurch (Nolte 2000, S. 244)? Wie bekämpften sie sich gegenseitig? Welche Sichtweisen wurden hierbei hegemonial, welche gerieten in Vergessenheit oder kamen gar nicht erst in den Blick wissenschaftlicher Aufmerksamkeit? Wenn Wissenschaft immer auch ein sozialer Prozess ist, wie die Wissenschafts-, Wissens- und Kultursoziologie gezeigt haben, dann gilt dies nicht zuletzt auch für die Soziologie selbst.

\section{Die Institutionalisierung der Kölner Vierteljahrshefte für Soziologie}

Das Sonderheft beginnt mit Leopold von Wieses Gründungsartikel der Vorläuferzeitschrift der KZfSS, den Kölner Vierteljahrsheften für Sozialwissenschaften von 1921. Die Kölner Vierteljahrshefte stehen in unmittelbaren Zusammenhang mit der von Konrad Adenauer noch vor Kriegsende initiierten Einrichtung des ersten Forschungsinstituts im Bereich der Soziologie, dem 1919 gegründeten „Forschungsinstitut für Sozialwissenschaften“ in Köln (vgl. von Alemann 1981, S. 349; Gorges 1986, S. 97 ff.; Kaesler 1997, S. 235; Schad 1972, S. 49 ff.). Die Aufgabe des Instituts, das von der Stadt Köln finanziert wurde, bestand laut dessen Verwaltungsdirektor Christian Eckert in der Analyse sozialrechtlicher, -wirtschaftlicher und -politischer Probleme (von Alemann 1981, S. 352). Wie von Wiese in seinen Erinnerungen berichtet, sollte unter dem Eindruck der für das Bürgertum schockierenden Novemberrevolution 1918 (vgl. von Wiese 1957, S. 57; Gorges 1986, S. 99) und angesichts einer weiteren ,drohenden sozialen Revolution“ (von Wiese 1957, S. 52) das politische Ziel der Forschungen die ,soziale Frage“ sein. ${ }^{4}$ Entsprechend der damaligen Aufteilung der rheinländischen Parteien in Zentrum, Sozialdemokratie und Liberale wurde das Institut auf Betreiben Adenauers untergliedert in eine soziologi-

\footnotetext{
${ }^{4}$ Der erste Soziologentag nach dem Ersten Weltkrieg 1922 in Jena hatte „Das Wesen der Revolution“ zum Thema, ohne jedoch, in Angst vor allzu viel Werturteil, konkret auf die aktuelle Relevanz einzugehen (vgl. Gorges 1986, S. 87; van Dyk und Lessenich 2008). Die Reaktivierung der DGS war vor allem Ferdinand Tönnies und Werner Sombart zu verdanken (vgl. Stölting 1986, S. 198; Dörk 2016); von Wiese versuchte innerhalb der DGS seine Beziehungslehre prominent zu propagieren. In Tönnies' Eröffnungsrede des Soziologentages 1922 weist dieser in Kenntnis von von Wieses Aufsätzen in den Vierteljahrsheften der Beziehungslehre eine zentrale Rolle für die Soziologie zu (vgl. Kaesler 2008, S. 85). Von Wiese hält dann auch das Hauptreferat des Soziologentages 1922, sein Thema: „Die Problematik einer Soziologie der Revolution“. Scharfe Kritik daran gibt es lediglich von Carl Grünberg und insbesondere von dem Austromarxisten Alfred Adler, dem ,eigentlichen Opponent zur Kölner Beziehungslehre“ (Kaesler 2008, S. 86).
} 
sche, eine sozialpolitische und eine sozialrechtliche Abteilung (vgl. von Wiese 1957, S. 52; von Alemann 1981, S. 349 f.; Gorges 1986, S. 100 ff.), wobei letztere erst 1928 eingerichtet wurde. Wie Adenauer im März 1918 vor der Stadtverordnetenversammlung festhielt, sollten damit unterschiedliche Forschungsrichtungen repräsentiert sein, ,nämlich ,eine auf christlichem, eine auf sozialistischen Boden stehende und eine, die sich dem verfeinerten kapitalistischen und Unternehmerstandpunkte nähert““ (zitiert nach von Alemann 1981, S. 351). Leopold von Wiese und Max Scheler standen der soziologischen Abteilung vor (ohne dass es jedoch zu irgendeiner inhaltlichen Zusammenarbeit kam), Hugo Lindemann der sozialpolitischen, Theodor Brauer dann einige Jahre später der sozialrechtlichen. ${ }^{5}$ Erste soziologische Assistenten waren Paul Honigsheim, Anny Ohrnberger und Maria Scheu (vgl. Gorges 1986, S. 101). Die Kölner Vierteljahrshefte für Sozialwissenschaften wurden ebenfalls unterteilt in eine Reihe A: Soziologische Hefte (1921) und Reihe B: Sozialpolitische Hefte (1922), aber bereits 1923 von Leopold von Wiese als zwei eigenständige Zeitschriften bis zu ihrer Einstellung 1934 geschäftsführend herausgegeben: die Kölner Vierteljahrshefte für Soziologie, die 1922 ab Heft 4. des 2. Jahrgangs dann auch Mitteilungsorgan der Deutschen Gesellschaft für Soziologie (DGS) wurden, und die Kölner sozialpolitische Vierteljahresschrift.

Wie Dirk Kaesler (1997, S. 235) hervorgehoben hat, ist das Gründungsjahr des Forschungsinstituts insofern bedeutsam, als 1919 mit der Berufung von drei Professoren mit der venia legendi in Soziologie erste Institutionalisierungsschritte des Faches an neu gegründeten Universitäten eingeläutet wurden. Franz Oppenheimer begann in Frankfurt am Main auf dem ersten Soziologie-Lehrstuhl (vgl. Caspari und Lichtblau 2014), in Köln wurden Leopold von Wiese auf den Lehrstuhl für wirtschaftliche Staatswissenschaften und Soziologie sowie Max Scheler auf den Lehrstuhl für Philosophie und Soziologie berufen. Weitere Zentren der Soziologie zu Beginn bis Mitte der 1920er-Jahre (vgl. Lepsius 1981a, S. 11; Stölting 1986, S. 105 ff.) waren Heidelberg (Alfred Weber, Emil Lederer), Kiel (Ferdinand Tönnies), Göttingen (Andreas Walther), Münster (Johann Plenge), Marburg (Max Graf zu Solms), Leipzig (Hans Freyer) und Berlin (Werner Sombart, Alfred Vierkandt, Kurt Breysig, Richard Thurnwald, Karl Dunkmann).

Die Gründung der Zeitschrift ist ein wichtiger Baustein der Bemühungen Leopold von Wieses, die Soziologie im wissenschaftlichen Feld der Weimarer Republik zu institutionalisieren, abzusichern und ihr zu Respektabilität zu verhelfen (vgl. Kaesler 1997, S. 240 und S. 242). Wie man anhand des vorliegenden Einführungstext „Die gegenwärtigen Aufgaben einer deutschen Zeitschrift für Soziologie“ lesen kann, bedarf es dafür in von Wieses Augen angesichts der vergangenen Kontroversen und Methodendebatten, insbesondere des Werturteilsstreits (vgl. Albert 2010), einer Herstellung einer tragfähigen Eintracht aller Soziologen (vgl. Kaelser 1984, S. 464; Gorges 1986, S. 106; Stölting 1986, S. 169). Anhand der Zeitschrift, so von Wiese (1921, S. 5/75, s. Tab. 1), ,soll in Aussprache und Kritik ein Weg gefunden werden, der aus dem schon so lange andauernden Methodenstreite zu aufbauender Arbeit

\footnotetext{
5 Wie von Alemann (1981, S. 367, 373) berichtet, hat es jedoch in der soziologischen Abteilung keine größere empirische Forschung gegeben, die Abteilung war mit Blick auf von Wiese insofern zuvorderst Redaktionsbüro der Zeitschrift und Verwaltungsbüro der DGS.
} 
führt". Die in der frühen deutschen Soziologie üblichen (und bis heute andauernden) Klagen über die Vielzahl an Perspektiven, chaotischen Zuständen und politischen Färbungen der Soziologie begegnet von Wiese, in der selbsternannten Rolle des „Friedensstifters“ (vgl. Kaesler 1997, S. 240), mit der Verordnung „strengste[r] Objektivität“ (von Wiese 1921, S. 6/76, s. Tab. 1) und politischer Neutralität.

Insbesondere die Verkündung politischer Neutralität, die ja nie wirklich eine ist, stellt eine der zentralen professionspolitischen Strategien von Wieses dar, die Soziologie im wissenschaftlichen Feld der ideologisch aufgeheizten Situation der frühen Weimarer Republik institutionell zu verankern. Darum will er sie auch explizit von der Sozialpolitik getrennt wissen: „Wir werden uns nur auf theoretische Fragen beschränken und alle Probleme der angewandten Soziallehren, alle Kunstlehren, alle Politik, besonders Sozialpolitik (der ja auch die andere selbstständige Reihe der Kölner Vierteljahrshefte gewidmet ist) und alle Fragen der Kultur- und Wohlfahrtspflege ausschließen“ (von Wiese 1921, S. 7/77, s. Tab. 1; Herv.i.O.) ${ }^{6}$.

Die „,boundary work“ (Gieryn), das heißt, die Abgrenzung der Soziologie von der als halbwissenschaftlich gebrandmarkten Sozialpolitik wäre nicht nötig gewesen, wie Paul Nolte in seiner Darstellung der deutschen Soziologie zu Recht hervorhebt, ,denn nach den grundsätzlichen Klärungen Max Webers schon im Jahre 1904 [Objektivitätsaufsatz, S.M.] konnte die Sozialpolitik, Werturteilsstreit hin oder her, einen seriösen Platz innerhalb der Sozialwissenschaften beanspruchen“ (Nolte 2000, S. 137). Notwendig war die Distinktion aber vor allem, wenn man von Wieses Institutionalisierungskalkül auch als Strategie betrachtet, die nicht nur nach allgemeiner Respektabilität der Soziologie trachtet, sondern eine ganz bestimmte Art von Soziologie zur Dominanz verhelfen will. Hatte Carl Heinrich Becker, Unterstaatssekretär im preußischen Kultusministerium, in seinen viel beachteten und debattierten „Gedanken zur Hochschulreform“ 1919 der Soziologie eine zentrale politische Rolle als Universal- und Reeducation-Wissenschaft der Deutschen zugesprochen (vgl. Nolte 2000, S. 134; Stölting 2006, S. 22), so propagiert von Wiese eine Soziologie als „klar umrissene Einzelwissenschaft“ mit einem einheitlichen Begriffssystem, besser mit seinem Verständnis von Soziologie als Beziehungslehre (1957, S. 53). „Es war sein Grenzziehungsvorschlag der neuen Disziplin und ihm wurde ein besonderer Teil reserviert“ (Stölting 1986, S. 169). So heißt es in der Einleitung, es wird in der Zeitschrift ein spezieller Teil jedes Heftes als „Archiv der Beziehungslehre“ der Soziologie die Richtung eröffnen, ,,von der sich die Redaktion die eigentliche Förderung unserer soziologischen Erkenntnis verspricht" (von Wiese 1921, S. 9/78, s. Tab. 1; vgl. auch von Wiese 1957, S. 61). Die erfolgreiche Institutionalisierung und Professionalisierung könne sich also nur mit seiner Art von Soziologie als Beziehungslehre und in Abgrenzung zu marxistischen, historischen und kulturphilosophischen Soziologievarianten vollziehen. Gestärkt wurde von Wieses ,gate-keeper“-Position dadurch, dass er nicht nur über ein Institut mit eigener

\footnotetext{
${ }^{6}$ Diese scheinbare politische Neutralität der Kölner hatte jedoch auch den Nebeneffekt des Reputationsgewinns für andere Akteure im Feld, auf den Erhard Stölting (2006, S. 21) hingewiesen hat: „Die zentralen Debatten der Weimarer Zeit zur ,Sozialisierung', zum neuen Mittelstand bis hin zum Faschismus und der ,organischen Gesellschaft ‘ wurden in dem von Weber mitbegründeten Archiv für Sozialwissenschaft und Sozialpolitik geführt, das auf diese Weise nach heutigen Maßstäben zum wichtigsten deutschsprachigen Organ jener Zeit überhaupt wurde.“.
} 
Zeitschrift, sondern als Erster Schriftführer, Organisator der Soziologentage und als Redakteur der Zeitschrift, die als Mitteilungsorgan der DGS fungierte, auch über auBerordentlichen Einfluss auf die Deutsche Gesellschaft für Soziologie verfügte (vgl. Gorges 1986, S. 97). „Nimmt man hinzu, daß der Besprechungsteil ebenfalls vor allem von von Wiese und solchen, die ihm nahestanden, gestaltet wurde, wird die strategische Platzierung der Position Wieses deutlich. Im Besprechungsteil wurden die Neuerscheinungen, die für die Soziologie als Fach wichtig erachtet wurden, mit einem beziehungswissenschaftlichen Auge gemustert, und das Resultat erschien als halboffizielle Meinung der DGS“ (Stölting 1986, S. 170).

Institut, Zeitschrift, Einfluss auf die DGS, geschicktes Lavieren durch die politischen Lager - von Wiese erscheint uns heute rückblickend als Prototyp eines erfolgreichen homo academicus:

„Karriereorientiert und institutionenbewußt tritt er uns im Rückblick entgegen: sämtliche institutionellen Instrumente der Reputations- und Einflußerlangung standen ihm nicht zur Verfügung, er hatte sie sich größtenteils selbst geschaffen. [...] [Er verfügte] buchstäblich über alles, was in den Rezeptbüchern der Wissenschaftssoziologie steht, um zu innerwissenschaftlicher Reputation und andauernder Klassizität zu gelangen“ (Kaesler 1997, S. 236 f.).

Bei allen feldspezifischen Abgrenzungen und Versuchen der Reputationsgewinnung war von Wieses (und auch Alfred Vierkandts) formale Soziologie aber zu Beginn der Weimarer Republik auch dazu geeignet, eine ,integrative Wirkung“ zu entfalten, ,gerade weil sie sich vordergründig nicht auf bestimmte ideologische Glaubensbekenntnisse festlegte“ (Nolte 2000, S. 140). ${ }^{7}$ Sie war zudem auch Reibungspunkt, an dem man als Kritiker nicht vorbeikam, was letztlich, versteht man Debatten und Kontroversen mit Georg Simmel ebenfalls als Integrationsfaktoren (vgl. Kneer und Moebius 2010), zu einer gewissen Kohäsion der Soziologie beitrug. Insofern sind Leopold von Wieses Einsätze ambivalent zu bewerten, denn sie führten nicht nur zur institutionellen und organisatorischen Stärkung seiner Soziologie, sondern der Soziologie insgesamt (vgl. Kaesler 1997, S. 242). Die Soziologie begann seitdem ihre fachdisziplinäre Professionalisierung und Ausdifferenzierung (vgl. Stölting 1986), von Wiese hatte daran auf institutioneller (und weniger auf inhaltlicher) Ebene entscheidenden Anteil. Und seine Beziehungslehre? Diese wurde zwar aufgrund der erfolgreichen Institutionalisierungsbemühungen von Wieses durchaus wahrgenommen und galt zu Beginn der 1920er-Jahre als eine der bedeutendsten Soziologieströmungen (vgl. Kaesler 2008, S. 85), bei späteren Generationen blieb sie jedoch, sieht man etwa von der zeitweisen Schülerschaft Howard Beckers ab, nahezu wirkungslos (vgl. Shils 1975, S. 78; von Alemann 1981, S. 359 ff.).

In der Gründungsausgabe der Vierteljahrshefte publizierten neben von Wiese (der hier abgedruckte Text sowie ein Aufsatz über die Methodologie der Beziehungslehre) auch Max Scheler mit einem wissenssoziologischen Aufsatz über die Aufgaben einer Soziologie der Erkenntnis, Ferdinand Tönnies über die DGS, Christian Eckert

\footnotetext{
7 Diese Neutralität sollte sich jedoch, wie Nolte (2000, S. 141 f.) betont, um 1930 zunehmend als ,Illusion“ entpuppen, als die Nähe der formalen Soziologie und ihrer Bezugsgröße der „Gruppe“ zu rechten Gesellschaftslehren zunahm.
} 
über die Aufgaben des Forschungsinstituts, und Alfred Vierkandt zum Programm einer formalen Gesellschaftslehre. ${ }^{8}$ In den Folgejahren kamen unter anderem neben den Genannten als Autoren auch Rudolf Goldscheid, Hans Kelsen, Wilhelm Jerusalem, Robert Michels, Richard Thurnwald, Werner Sombart, Andreas Walther, Max Graf zu Solm, Paul Ludwig Landsberg, Friedrich Hertz, Franz Oppenheimer, Carl Brinkmann, Karl Dunkmann, Rudolf Heberle, Theodor Geiger, Othmar Spann, Max Rumpf, Robert E. Park, Pitrim A. Sorokin, Sebald Rudolf Steinmetz, Charles Bouglé, Helmuth Plessner, Howard Becker, Johann Plenge und Karl Mannheim. Auch einige Frauen finden sich unter den Autoren wieder, etwa Käthe Bauer-Mengelberg, Maria Steinhoff, Hanna Meuter, Gertrud Faßhauer oder Charlotte von Reichenau.

\section{Das Feld der soziologischen Zeitschriften in der Weimarer Republik}

Wenige Jahre nach Erscheinen der Vierteljahrshefte wurden, als sich die ökonomische Grundlage für derartige Projekte verbesserte, weitere soziologische Zeitschriften ins Leben gerufen. ${ }^{9}$ Zu nennen sind hier das 1925 von Gottfried Salomon gegründete Jahrbuch für Soziologie, von dem allerdings nur drei Bände erschienen. Es sollte sowohl empirischer als auch internationaler ausgerichtet sein als die Vierteljahrshefte. Zu Autoren des Jahrbuchs zählten beispielsweise Celestin Bouglé, Maurice Halbwachs, Robert H. Lowie, René Maunier, Robert Michels, Gaetano Mosca, Pitrim A. Sorokin, Yasama Takata, Tönnies, Vierkandt, aber auch von Wiese. Auf größere Internationalität gerichtet war die ebenfalls von Salomon 1926 herausgegebene soziologische Abteilung des von Ludwig Stein gegründeten Archivs für systematische Philosophie (vgl. Stölting 1986, S. 175). Von 1925 bis 1927 existierte außerdem die Zeitschrift Ethos. Vierteljahresschrift für Soziologie, Geschichtsund Kulturphilosophie, herausgegeben von dem aus Kiew nach Berlin geflohenen David Koigen. Soziologische Autoren der Zeitschrift waren unter anderem Tönnies, Vierkandt, Dunkmann, Geiger, Michels oder Walther. International sichtbarer und profilierter als Salomons Jahrbuch oder Koigens Ethos war jedoch Richard Thurnwalds und Bronislaw Malinowskis ebenfalls seit 1925 herausgegebene Zeitschrift für Völkerpsychologie und Soziologie (ab 1932 hieß sie Sociologus). Anders als die Kölner Viertelsjahrshefte für Soziologie öffnete sich Thurnwalds Zeitschrift ausdrücklich sowohl der praktisch-politischen Verwendung soziologischen Wissens (vgl. Stölting 1986, S. 180) als auch der empirischen Forschung und rezipierte schon vor 1945 die amerikanische Sozialforschung. Darum spielte hier auch die Internationalität eine weitaus größere Rolle. Die Zeitschrift enthielt im Vergleich zu den Vierteljahrsheften, Salomons Jahrbuch oder dem Archiv für Sozialwissenschaften und Sozialpolitik den ,höchsten Anteil expliziter internationaler Beiträge“ (Sieg 2002, S. 144; vgl. Stölting 1986, S. 184). So waren nicht nur etwa William F. Ogburn, Edward Sapir, Sorokin oder Steinmetz im Laufe der Jahre Mitherausgeber, sondern die Zeitschrift erschien ab 1932 auch zweisprachig unter dem erweiterten

\footnotetext{
8 Vgl. Gorges (1986, S. 108 f., S. 289-292 und S. 495-498), dort ist auch ein detaillierter Überblick über weitere Autoren und Themengebiete zu finden; vgl. auch Stölting (1986, S. 170 f., FN. 74).

9 Zum Folgenden greife ich insbesondere auf die Angaben in Stölting (1986, S. 172 ff.) zurück.
} 
Untertitel A Journal of Sociocology and Social Psychology, ein Titel, der, vermittelt über den Thurnwald-Schüler René König, nicht zufällig an den Titel der KZfSS seit 1955 erinnert. ${ }^{10}$ Clemens Albrecht (2013, S. 402) hat die Stoßrichtung der Zeitschrift Thurnwalds folgendermaßen umschrieben: „Es ist ein massives Plädoyer für eine Soziologie als Gegenwartswissenschaft, die mit Hilfe von quantitativen empirischen Methoden ein Wissen erhebt, das mit der strukturfunktionalistischen Theorie gedeutet und für die praktisch-politische Anwendung dienstbar gemacht werden kann." Allerdings korrespondiert die Internationalität negativ mit der Beteiligung deutscher Soziologen. Die Zeitschrift wirkte nicht so sehr wie die Vierteljahrshefte, in die sich institutionalisierende deutsche Soziologie, was eventuell mit der Breite des unter anderem auch ethnologisch angereicherten Ansatzes oder vielleicht auch gerade mit der internationalen Öffnung zusammenhängen mag (vgl. Stölting 1986, S. 180).

Von 1928 bis 1933 erschien als Nachfolge der 1924 publizierten Zeitschrift Nordland des Berliner Instituts für angewandte Soziologie das Archiv für angewandte Soziologie von Karl Dunkmann. Das Archiv griff ein viel diskutiertes Thema auf (vgl. Plessner 2002) und propagierte eine neue Volksgemeinschaft; Soziologie war aus dieser Sicht eine „Wissenschaft im Dienste einer Volksreform“ (Stölting 1986, S. $186 \mathrm{f}$.).

Das war das Feld der soziologischen Zeitschriften, in die die Vierteljahrshefte eingeordnet werden können. ${ }^{11}$ Natürlich spiegeln die Publikationsorgane nicht die gesamten Konstellationen des soziologischen Feldes der 1920er-Jahre wider (vgl. König 1961; Stölting 1986; Gorges 1986; Nolte 2000), aber sie geben Aufschluss über einige Positionen und Diskurse, die für die Genese des Feldes wesentlich waren. Denn die durchaus unterschiedlichen Aussagen darüber, was Soziologie sei, hemmten deren Institutionalisierung nicht, sondern begünstigten vielmehr die Konstituierung eines soziologischen Diskursfeldes:

\begin{abstract}
„Diese Vielfalt aber, so sehr sie offenbar die Grenzen der Disziplin verschwimmen ließ, förderte in anderer Hinsicht den Institutionalisierungsprozeß doch. Denn indem die Soziologen darum stritten, was ,Soziologie' sei und was sie zu sein habe, bezogen sie sich auf etwas, dessen Existenz und Berechtigung sie damit gerade unterstellten. Indem sich die übrigen soziologischen Zeitschriften immer, wenn auch negativ, auf Wieses Zeitschrift bezogen, bestätigten sie gerade sein Streben nach Institutionalisierung, ohne daß Wiese selbst sich dessen gewahr wurde“" (Stölting 1986, S. 191).
\end{abstract}

\footnotetext{
${ }_{10}$ Vgl. Albrecht (2013, S. 400); Moebius (2015, S. 57 f.). König schrieb in Thurnwalds Zeitschrift auch seinen ersten Artikel über „Die neuesten Strömungen in der gegenwärtigen französischen Soziologie“ (1931/1932), der ebenfalls auf die Bedeutung der Rezeption internationaler Soziologie verweist (vgl. Moebius 2015, S. 57; vgl. auch König 1973, S. IX f.).

${ }^{11}$ Die Frankfurter Zeitschrift für Sozialforschung habe ich hier außen vor gelassen, da sie erst 1932 gegründet wurde.
} 


\section{Der Streit um die Wissenssoziologie und die ,neue soziologische Welle“6}

In den Kontext der soziologischen Debatten der Zwischenkriegszeit gehören auch die beiden, hier abgedruckten generationssoziologischen Artikel von Karl Mannheim. Dieser hatte sich Mitte der 1920er-Jahre von der Kultursoziologie kommend mehr und mehr der Wissenssoziologie zugewendet (vgl. Barboza und Lichtblau 2009, S. 12 f.; Blomert 1999, S. 183 ff.; Lichtblau 1996, S. 492 ff.) und 1925 in Heidelberg bei Alfred Weber, Carl Brinkmann und Emil Lederer seine wissenssoziologische Habilitationsschrift über Konservatismus eingereicht. Ebenfalls 1925 erschien sein Aufsatz „Problem einer Soziologie des Wissens“ im Archiv für Sozialwissenschaft und Sozialpolitik. Die Kulturprozesse und Weltanschauungen, so Mannheim, ihre Formen, Inhalte und Geltungen seien rückgebunden an die jeweiligen sozio-historischen Standorte, konjunktiven Erfahrungsräume und Generationserfahrungen. Sie stünden in einem funktionalen Verhältnis zu den Seinslagen, was Mannheim dann als ,Seinsverbundenheit des Wissens“ bezeichnete (Mannheim 1931, S. 660). Die Analyse der Generationslagerungen, wie er sie in den beiden vorliegenden Aufsätzen vornimmt, erlaubte ,eine noch differenziertere Weltanschauungsanalyse“ (Barboza und Lichtblau 2009, S. 23). Mannheim unterscheidet zwischen „Generationslagerung“ (,dieselbe historische Lebensgemeinschaft“ qua Geburt), „Generationszusammenhang“ („Partizipation an den gemeinsamen Schicksalen“ und geteilter Problemhorizont) und „Generationseinheit“" (spezifische Verarbeitung und zuweilen auch gegensätzliche Reaktion auf Problemhorizont etwa im Sinne eines liberalen oder konservativen Denkstils).

Die beiden Artikel erschienen 1928 in den Vierteljahrsheften, ihnen zugehörig ist ein weiteres Ereignis im selben Jahr, das Mannheim zum jungen und heiß debattierten ,shooting star“ (Matthiesen) in und außerhalb der Soziologie avancieren ließ. Sein Vortrag auf dem 6. Deutschen Soziologentag in Zürich über die „Konkurrenz auf dem Gebiete des Geistigen“, der zusammen mit dem 1929 erschienenen Buch Ideologie und Utopie den ,Streit um die Wissenssoziologie“ (vgl. Srubar 2010) auf die Spitze trieb und ein „Aufstand im Herzen der DGS“ (König 1987, S. 356) darstellte. „Vertreter aller Generationen der deutschen Gelehrten“ (vgl. Srubar 2010, S. 60 ff.), von Alfred Weber und Werner Sombart bis hin zu Otto Neurath, Max Horkheimer, Ernst Robert Curtius, Max Adler, Hannah Arendt, Herbert Marcuse oder Karl August Wittvogel, alle diskutierten kontrovers Mannheims Thesen (vgl. Meja und Stehr 1982) und warfen ihm entweder Soziologismus, Relativismus, soziologischen Materialismus oder „Submarxismus“ vor und bestätigten damit zugleich seine Wissenssoziologie von der Konkurrenz auf dem Gebiete des Geistigen.

„Es ist ein subtiler Witz der Soziologiegeschichte, daß genau im gleichen Jahr 1928 eine Abhandlung von Mannheim über ,Das Problem der Generationen' in den Kölner Vierteljahrsheften für Soziologie, Bd. 7, veröffentlicht wurde, die von einem der Hauptverantwortlichen, dem ,ewigen' Schriftführer des Establishments Leopold von Wiese herausgegeben wurde [...]. Die Bedeutung des Witzes lag darin, daß ausgerechnet mit diesem Thema eine Generationsablösung von einem Mitglied dieser neuen Generation angebahnt worden war, ferner wird damit eine ganze Reihe von neuen Themen eingeläutet [...]“ (König 1987, S. 353). 
Es ging Mannheim mit seiner These der Seinsverbundenheit und Konkurrenz der Denkstile eigentlich um eine Verständigung zwischen den Positionen. Auch er war auf der Suche nach einer einheitlichen Perspektive. Insbesondere den sozial „freischwebenden Intellektuellen“ sprach er die Fähigkeit zu, eine Vogelperspektive einzunehmen und zwischen den Teilperspektiven eine relationale Synthese herzustellen. So landete er ,am Ende beim Traum einer Synthese und bei der Erhöhung der Intellektuellen über das irdische Reich der Ideologie“" (Ringer 1987, S. 384) und war damit von den Positionen seiner Kritiker nicht mehr weit entfernt.

Mannheims Aufsätze, Vorträge und Bücher sind für König (1987, S. 353 ff.) der Beweis, dass die Melodien der Soziologie vor 1933 noch längst nicht alle durchgespielt waren, wie Schelsky (1959, S. 37) behauptet hatte, allerdings sei diese ,neue Welle“ aber vom „Establishment“ der DGS schnell ausgebremst worden (König 1987, S. 355 ff.).

Zu dieser „,neuen Welle“ der Weimarer Soziologie zählt König (1987, S. 380) auch den von ihm so betitelten „militanten Humanisten“" Theodor Geiger. Dessen vorliegender Aufsatz „Natürliche Auslese, soziale Schichtung und das Problem der Generationen“ (1933/1934) erschien im letzten 12. Jahrgang der Kölner Vierteljahrshefte für Soziologie in einer der neuen Rubriken der Zeitschrift, dem seit 1932 eingerichteten speziellen Teil „Biosoziologie“. ${ }^{12}$ Der Aufsatz ist Teil einer Reihe von Texten und Büchern zum Thema Eugenik und Sozialpolitik Geigers. ${ }^{13}$

In der soziologiehistorischen Forschung gibt es unterschiedliche Interpretationen und Bewertungen, was Geigers Texte über Eugenik anbelangt. Auf der einen Seite wird ihm vorgeworfen, er sei für „Auslese- und Ausmerzungsmaßnahmen“ eingetreten (Pinn 1987, S. 230) und habe sich damit dem Nationalsozialismus angedient. Thomas Meyer (2001, „Die Soziologie Theodor Geigers“, S. 115 ff.) deutet in seiner, den sozialdemokratischen Diskurs berücksichtigenden, differenzierten Analyse, die auch Geigers Kritik an der Eugenik würdigt, dessen Haltung und Wortwahl als Befürwortung einer ,autoritären Bevölkerungspolitik“ (Meyer 2001, „Die Soziologie Theodor Geigers“, S. 130), weil dieser etwa, trotz seiner Kritik am Nationalsozialismus, unter bestimmten Bedingungen Zwangssterilisationen für sinnvoll erachtete. Auf der anderen Seite wird Geigers soziologische wie auch naturwissenschaftlichinformierte Kritik an der auf einem naiven Verständnis von Genetik beruhenden bio-

\footnotetext{
12 Stölting (1986, S. 171, FN. 74) schreibt zu dieser Ergänzung, zu der 1933/34 noch „Betriebssoziologie“ und ,Sozialpädagogik“ hinzukamen: „Die Erweiterung der Vierteljahreshefte um die Abteilung ,Biosoziologie" war recht schlitzohrig: Die dort aufgenommenen Artikel gaben weder NS-Ideologie wider, noch fielen sie aus dem bisherigen Spektrum der Zeitschrift.“ Man könnte es aber auch als „Anpassung an den herrschenden Zeitgeist" und den immer populärer werdenden rassenhygienischen Diskurs bezeichnen (Pinn und Nebelung 1990, S. 190).

13 Geiger war 1928 auf eine Soziologieprofessur an die Technische Hochschule Braunschweig berufen worden. Er erfuhr in der Zwischenkriegszeit insbesondere durch Die Masse und ihre Aktion (1926), zentrale Artikel (zu Soziologie, Gemeinschaft, Gesellschaft, Revolution und Führung) in Vierkandts Handwörterbuch (1931) und Die soziale Schichtung des deutschen Volkes (1932) auch international große Anerkennung. 1933 emigrierte Geiger, der viele Jahre der SPD angehört und die in Braunschweig geplante Professur für Gesellschaftslehre für Adolf Hitler verhindert hatte sowie die NSDAP bereits seit etlichen Jahren öffentlich kritisierte, nach Dänemark. Dort wurde er 1938 erster dänischer Soziologieprofessor. Nach 1945 aus dem Exil in Schweden nach Dänemark zurückgekehrt, beteiligte sich Geiger als Repräsentant der skandinavischen Länder bei der Gründung der International Sociological Association (ISA).
} 
logischen Grundlegung der Eugenik und an der eugenischen Bewegung sowie seine Verteidigung sozialpolitischer gegenüber biopolitischen Maßnahmen besonders hervorgehoben (vgl. Holzhauser i. V.; Schwartz 1995, S. 159). ${ }^{14}$ Der vorliegende Text ist jedenfalls als eine Kritik an vorherrschenden Auffassungen der „Erbpflegepolitik“ und Eugeniker zu betrachten, die Sozialpolitik für überflüssig oder gar schädlich hielten. Anders Geiger, der die „Erbpflege“ für viel unbedeutender als Sozialpolitik erachtet und in seinem Beitrag die gesellschaftlichen sowie historischen Aspekte der Sozialstruktur ins Zentrum rückt. Denn, wie Geiger im vorliegenden Aufsatz (1933/34, S. 161/122, s. Tab. 1) schreibt, beruhe die ursprüngliche soziale Schichtbildung ,meist nicht auf natürlicher Auslese innerhalb eines menschlichen Lebensverbandes, sondern auf Unterwerfung einer Gruppe durch eine andere [...].“ Soziale Schichtung sei darum auch nicht das Ergebnis ,natürlicher Auslese“. Geiger versucht den Erbpflegediskurs aus einer historischen und wissenssoziologischen Perspektive zu entkräften, indem er auf den historisch kontingenten und herrschaftsmäßigen Charakter von Bewertungsmaßstäben verweist. Soziale Rangunterschiede lassen sich nicht aus der Biologie ableiten, im Gegenteil: die ,soziale Einschätzung bestimmter Anlagetypen, die sich (angeblich) in einzelnen sozialen Schichten gehäuft vorfinden, ist geschichtlich bedingt und schwankt mit dem Wechsel des Kulturstils. [...] Die Varianten der natürlichen Anlagen und Begabungen können nicht nach biologischen Wertungen verglichen werden, sondern erhalten in der Gesellschaft ihren Rangplatz nach Maßgabe der in der Epoche gültigen Rangordnung der Werte“ (Geiger 1933/34, S. 165/138, s. Tab. 1). Weder der Schichtwechsel noch die Zughörigkeit zu einer bestimmten sozialen Schicht lassen sich in seinen Augen mit dem Theorem der natürlichen Auslese erklären, ja mehr noch, dieses Theorem ist als Ausdruck symbolischer Macht und Ideologie der Herrschenden zu dekonstruieren: „Wie die Annahme generativer Überwertigkeit der gehobenen Schichten eine Selbstverherrlichungsideologie der oben Geborenen ist, so ist die These vom ,Aufstieg der Tüchtigen“ eine Ideologie der im Aufstieg Erfolgreichen“, wie Geiger (1933/34, S. 173/133, s. Tab. 1), manche Annahmen Pierre Bourdieus vorwegnehmend, schreibt.

\section{Schließung des Kölner Forschungsinstituts und Einstellung der Vierteljahrshefte}

Mit der Schließung des gesamten Instituts am 31. März 1934 wurden die Vierteljahrshefte eingestellt. „Vordergründig mag ein Grund für die Schließung in den Sparmaßnahmen der Stadt Köln gelegen haben, gewiss war aber auch ausschlaggebend, wie von Wiese im letzten Heft der Zeitschrift spekuliert, dass sich die Stadtväter und -mütter das Verhältnis des Instituts zu den herrschenden politischen Parteien enger vorgestellt hätten (von Wiese 1933/34, S. 2)“ (Dreier 2016, S. 4; vgl. auch Klingemann 1988, S. 79 f.; Pinn und Nebelung 1990, S. 189). Dadurch frei gewordene Gelder wurden in das Institut für Deutschen Sozialismus von Wilhelm

\footnotetext{
14 Für wertvolle Hinweise auf weitere Texte von Geiger zum Thema und zur differenzierten Sichtweise auf diese danke ich Nicole Holzhauser.
} 
Börger umgelenkt (vgl. Klingemann 1988, S. 80). Von Wiese, der als Ersatz für die Vierteljahrshefte ein letztlich nicht realisiertes Jahrbuch herauszugeben plante (vgl. Klingemann 1988, S. 79), setzte seine Lehre und Forschung als Ordinarius am Soziologischen Seminar der Universität fort. Die DGS wurde nicht ,von oben gleichgeschaltet“, wie von Wiese (1948a, S. 4), der eine Strategie der Selbstgleichschaltung verfolgte und seine Soziologie dem NS-Regime anzubieten versuchte (van Dyk und Schauer 2015, S. 47; Klingemann 1988, S. 82), später behauptete; sie wurde vielmehr von dem „1933 auf Vorschlag des Vorstands installierten ,Führers“ Hans Freyer 1934 stillgelegt.“ (Schnitzler 2016, S. 1); eine Stilllegung, die nicht das Resultat eines ,liberalen“ oder ,präventiven Rettungsaktes“, sondern einer spezifischen Konkurrenzsituation zwischen zwei Positionen geschuldet war, die sich dem Nationalsozialismus andienen wollten (vgl. van Dyk und Schauer 2015, S. 46 ff. und S. 144; Borggräfe und Schnitzler 2014, S. 454 und S. 458; Klingemann 1996, S. 11 ff.; Schäfer 1990, S. 141). Als Mitteilungsorgan der DGS firmierte nun der von Hans Freyer, Max Hildebert Boehm und Max Rumpf herausgegebene Volksspiegel. Zeitschrift für deutsche Soziologie und Volkswissenschaft (vgl. Stölting 1986, S. 192 f.; Borggräfe und Schnitzler 2014, S. 456), der sich dann mit sukzessivem Ausscheiden der Herausgeber zu einer nationalsozialistischen Zeitschrift für pädagogische Volksforschung und Volkstumsgestaltung wandelte. ${ }^{15}$

\section{Nach 1945: Wiederbegründung der Zeitschrift und zentrale Themen der westdeutschen Nachkriegssoziologie}

Die Wiederbegründung der Zeitschrift erfolgte 1948 unter dem Titel Kölner Zeitschrift für Soziologie. Neue Folge der Vierteljahrshefte für Soziologie. Angesiedelt war sie an der Soziologischen Abteilung des 1947 gegründeten Forschungsinstituts für Sozial- und Verwaltungswissenschaften (vgl. Haupts 2007, S. 116 ff.), Herausgeber war Leopold von Wiese. Dieser hatte bereits 1946 mit Unterstützung des USHICOG-Offiziers und guten Kenner des deutschen Wissenschaftssystem Edward Y. Hartshorne (vgl. Tent 1998) ${ }^{16}$ die DGS wiederbegründet (vgl. von Wiese 1959, S. 17), wurde deren erster Nachkriegspräsident und lud im September 1946 zum achten Soziologentag in Frankfurt am Main ein. Der Nationalsozialismus und die systematische Ermordung von Millionen von Menschen durch den Faschismus war keinem der Anwesenden eine soziologische Analyse wert - mit Ausnahme von Heinz Maus, der auf eine Soziologie des Nationalsozialismus drängte (vgl. Demi-

\footnotetext{
15 Da es hier um die Geschichte der Soziologie im Spiegel der Geschichte der KZfSS geht, kann die Soziologie im Nationalsozialismus nicht eigens thematisiert werden, vgl. aber u. a. Maus (1959), der wie Lepsius (1979, 1981b), Srubar (1988) oder Fleck (2007) auch die Soziologie im Exil anspricht, Stölting (1984), van Dyk und Schauer (2015) sowie Christ und Suderland (2014). Eine Kontinuität der Soziologie während des Nationalsozialismus sehen Klingemann (1996, 2009) und Rammstedt (1986), eine These, die nicht unwidersprochen blieb (vgl. etwa Lepsius 2008, S. 36 f.) und bis heute Debatten über Konitnuität oder Diskontinuität der Soziologie nach 1933 entfacht, siehe dazu instruktiv zusammenfassend und empirisch die Diskontinuitätsthese bestätigend Holzhauser (2015).

16 Hartshorne hatte u. a. 1937 eine kritische, empirische Studie über The German Universities and National Socialism verfasst.
} 
rovic 1999, S. 299 ff.; van Dyk und Schauer 2015, S. 152 ff.). Allgemein war aber Beschweigen, Verdrängen und Verlagerung ins Metaphysische die allgemeine Devise, wie anhand der Äußerungen in der Eröffnungsrede von Wieses (1948b, S. 29) über die von ,außen“" gekommene „Pest“ und das „metaphysische Geheimnis“, an dem ,der Soziologe nicht zu rühren vermag“, deutlich wurde. Die Mär von der Stilllegung als präventivem Rettungsakt war hingegen gegenüber den Alliierten für die Wiederbegründung der DGS hilfreich (vgl. van Dyk und Schauer 2015, S. 144 ff.).

Zentrale Themen der Nachkriegssoziologie waren die Industrie-, Familien- und Jugendsoziologie, soziale Klassen und Schichtung und Mobilität (vgl. Moebius 2016b). M. Rainer Lepsius (1979, S. 35) hat in einem Überblicksbeitrag zur Soziologie nach dem Zweiten Weltkrieg hinsichtlich der Akteure und regionalen Zentren festgehalten, die Grundkonstellation der westdeutschen Nachkriegssoziologie ,wurde bestimmt durch die vier neu entstandenen Zentren in Berlin, Frankfurt, Köln und Hamburg, zu denen noch als weitere Schwerpunkte Freiburg und Göttingen traten. An allen diesen Orten hatte die Soziologie einen eigenen Charakter, der durch die Lehrstuhlinhaber geprägt worden war. Es handelt sich noch um einen kleinen Personenkreis, der gebildet wurde von Max Horkheimer und Theodor W. Adorno in Frankfurt, Helmuth Plessner in Göttingen, René König in Köln, Arnold Bergstraesser in Freiburg, Helmut Schelsky in Hamburg, Otto Stammer in Berlin. [...] Gemeinsam unterstützen sie in den 1950er-Jahren eine Strategie, die die Soziologie als eigenständige und sich professionalisierende Disziplin etablieren wollte, und bei aller Unterschiedlichkeit der Erkenntnisinteressen und wissenschaftspolitischen Orientierungen förderten sie empirische Forschungen. Es erscheint gerechtfertigt, sie als die Gründergeneration der Nachkriegssoziologie zusammenzufassen [...]“ (Lepsius 1979, S. 35 f.).

Zwar gab es viele Differenzen (biografisch, ideologisch, habituell), aber was die „Charismatiker des Anfangs“ (Bude 2002) neben der gemeinsamen empirischen Ausrichtung vereinte, war der ,entschiedene Wille zur politischen und gesellschaftlichen Aufklärung über die konkreten Gegebenheiten und wirksamen Strukturen der Nachkriegssituation und der Zusammenbruchsgesellschaft“" (Bude 2002, S. 409). Die gesellschaftlichen Prozesse und Problemlagen der frühen Bundesrepublik waren insbesondere geprägt durch den industriellen und sozialstrukturellen Wandel in der fortgeschrittenen Industriegesellschaft. Das beinhaltete unter anderem das durch das „Wirtschaftswunder“ veränderte Konsum- und Freizeitverhalten, einen Strukturwandel der Familie und Urbanisierung. Politisch ging dieser Prozess mit der Westintegration, der Remilitarisierung, dem Verbot der KPD und der Verdrängung des Nationalsozialismus einher (vgl. Conze 2009, S. 184 ff.).

Als führende Soziologien der Nachkriegszeit (vgl. Dahrendorf 1960) galten die Kölner Schule um René König, die Frankfurter Schule sowie Helmut Schelsky (zunächst Hamburg, später Münster). ${ }^{17}$ Bei allen Unterschieden in ihrer Ausrichtung und wechselnden Koalitionen zwischen ihnen (vgl. Moebius 2015, S. 12 ff.) gab

\footnotetext{
17 Darüber sollten jedoch inhaltlich nicht die Bedeutung anderer wichtiger Vertreter der bundesrepublikanischen Nachkriegssoziologie vergessen werden, die allerdings in der vorliegenden Sammlung an Aufsätzen nicht oder nur am Rande aufscheinen, man denke etwa an die marxistisch orientierte Marburger Schule um Wolfang Abendroth und Werner Hofmann, an Otto Stammer, Helmuth Plessner, Arnold Bergstraesser; auch einige Jahrzehnte später gibt es wichtige Denkschulen, die im Folgenden nicht zur Sprache kommen
} 
es einen „generationsspezifischen Arbeitskonsens“ (Bude 2002, S. 413) und ähnliche Reaktionen auf die gesellschaftlichen Neustrukturierungen. So interessierten sich alle gleichermaßen für Industrie-, Gemeinde- und Familiensoziologie. Bereits 1946 hatte René König im Exil im Auftrag des Schweizerischen Bundesrats über Familie geforscht (vgl. Zürcher 1995, S. 242 ff.), eine Studie, auf der Schelskys erste Beschäftigung mit der Familie aufbaut (vgl. Tyrell 1986, S. 45). „Familie“ ist wegen ihrer ,kriegs- und nachkriegsbedingten Auflösungserscheinungen“ einerseits und ihres „Bedeutungsgewinns als Hort des Rückzugs“ andererseits (Conze 2009, S 187) im Nachkriegsdeutschland von besonderer Bedeutung. Betonten König und Schelsky den Integrations- und Stabilitätsfaktor von Familie, betrachteten Adorno und Horkheimer sie seit Mitte der 1930er-Jahre als Institution zur Einübung autoritätsfixierten Verhaltens, eine Institution, die aber in der Moderne immer mehr in Auflösung begriffen sei (vgl. Schäfer 1996, S. 385 ff.).

Der vorliegende Text von Helmut Schelsky (1951, s. Tab. 1) ist in diesem Zusammenhang zu sehen. Er ist Teil zahlreicher Aufsätze von ihm zur Familiensoziologie seit 1949 (vgl. Tyrell 1986, S. 54 f., FN 2, 5, 7) und greift als Thema die Flüchtlingsfamilie auf, die, so die zentrale These Schelskys, keine Ausnahme oder ein Gegensatz zur Familienverfassung der deutschen Gesellschaft darstelle, sondern die ,,ausgeprägteste und fortgeschrittenste Form“ einer Wandlung und Modernisierung der Familie in der Gegenwart repräsentiere (Schelsky 1951, S. 163/146 und S. 172/154, s. Tab. 1). Der Artikel baut auf einer empirischen Studie auf, die von Mitte 1949 bis Mitte 1950 von Studenten der Akademie für Gemeinwirtschaft in Hamburg durchgeführt und von dem Assistenten Gerhard Wurzbacher betreut wurde (vgl. Tyrell 1986, S. 45), der in einer eigenen Studie über die empirische Erhebung berichtet („Leitbilder des gegenwärtigen deutschen Familienlebens: Methoden, Ergebnisse und sozialpädagogische Folgerungen einer soziologischen Analyse von 164 Familienmonographien“, 1951). Erkennbar seien deutlich Prozesse des „Einigelns“ (Schelsky 1951, S. 173/155, s. Tab. 1), daraus resultierende „Überbeanspruchung der Intimgruppe“ (Schelsky 1951, S. 173/156, s. Tab. 1) und damit zusammenhängende Abwendung von Großorganisationen und Entpolitisierungstendenzen (Schelsky 1951, S. 173 f./156ff., s. Tab. 1). Schelsky kommt hier mit Blick auf das politische Desinteresse und der apolitischen Mentalität des „Ohne-uns“ zu Ergebnissen, wie sie zeitgleich David Riesman in The Lonely Crowd, zu dem Schelsky eine Einführung verfasst, aufgestellt hat und wie sie viele Jahre später durch Richard Sennetts Verfall und Ende des öffentlichen Lebens. Tyrannei der Intimität (1974) populär werden. Allerdings bemerkt Schelsky im Fokus auf die „Intimgruppe“ in der unmittelbaren Nachkriegszeit weniger eine ,neue Innerlichkeit“ als vielmehr eine Priorisierung des Ökonomischen, eine Enterotisierung und „Entinnerlichung“ (1951, S. 170/152, s. Tab. 1) sowie eine „Versachlichung“ (1951, S. 172/154, s. Tab. 1) der familiären Beziehungen. Die Konzentration auf Bildung, Beruf und Wiederaufstieg war aus dieser Sicht mithin Motor des sogenannten „Wirtschaftswunders“. Sozialtheoretisch macht Schelsky (1951, S. 176/157, s. Tab. 1) jedenfalls am Beispiel der (Flüchtlings-)Familie institutionelle Stabilisierungsprozesse aus, die sein zu dieser

können, beispielsweise die Konstanzer Schule um Thomas Luckmann oder poststrukturalistische Denkschulen. 
Zeit entwickeltes Theorem der institutionellen Elastizität, der „Stabilität im Wandel“ und des „stabilen Institutionenwandels“ verdeutlichen (vgl. Schäfer 2015a, S. 12; Wöhrle 2015, S. 61 ff.). Die Resultate der Studie, bereits im Oktober 1950 auf dem 10. Deutschen Soziologentag in Detmold vorgetragen, münden zusammen mit anderen Beiträgen in das 1953 veröffentlichte Buch Wandlungen der deutschen Familie in der Gegenwart. ${ }^{18}$

Der Beitrag gehört in die Hochphase Schelskys zum bundesrepublikanischen „Starsoziologen“, wie sie kürzlich Gerhard Schäfer (2015a) profund analysiert hat. $\mathrm{Zu}$ dieser Hamburger Phase, Schelsky war dort seit 1948 Professor an der Akademie für Gemeinwirtschaft, ab 1953 an der Universität, gehören auch die erfolgreichen Formeln der ,nivellierten Mittelstandsgesellschaft“ und der ,skeptischen Generation“ (Schäfer 2015a, S. 7; vgl. zu diesen „Formeln“ Wöhrle 2015, S. 125 ff. bzw. S. 87 ff.). ${ }^{19}$ Auch als Hochschullehrer war er durch zahlreiche Habilitationen und Promotionen wirkmächtig (vgl. Schäfer 2015a, S. 20 f.) und förderte neben Gerhard Wurzbacher, Rudolf Tartler, Janpeter Kob, Heinz Kluth, Friedrich Jonas, Hans-Jürgen Krysmanski, Renate Krysmanki, Lars Clausen, Luc Jochimsen, Renate Rausch, Thomas Neumann und vielen anderen ebenso Hans Paul Bahrdt, Heinrich Popitz, Arno Klönne sowie Ralf Dahrendorf (vgl. Schäfer 2015a, S. 3).

\section{Die Kölner Zeitschrift für Soziologie und Sozialpsychologie seit den 1955er-Jahren}

Im Laufe der 1950er-Jahre wurden die Distinktionen und Konkurrenzen zwischen den zentralen Schulen der bundesrepublikanischen Soziologie immer deutlicher (vgl. Moebius 2015, S. 17 f.). Die bereits bestandenen Unterschiede in der Beurteilung sowohl der gesellschaftlichen Prozesse und Probleme als auch hinsichtlich der Fundamente des eigenen Faches (philosophische oder empirische) nahmen zu und verdichteten sich zu Kämpfen um Definitions- und Repräsentationsmacht. Als René König 1955 die Herausgabe der Kölner Zeitschrift für Soziologie, wie sie damals hieß, übernahm, war er bereits international bekannt, hatte den ersten ISA-Kongress organisiert (von 1962-1966 war er gar ihr Präsident, der einzige deutsche bis dato) und avancierte immer mehr zum ,großen Übermittler empirischer Sozialforschung quantitativer Art" (Scheuch 2001, S. 144). Durch die Zeitschrift wurde die Position Königs und seiner „Schüler“ im soziologischen Feld wesentlich gestärkt (vgl. Moebius 2015). König benennt, durch Thurnwald vermittelt, die Zeitschrift in Kölner Zeitschrift für Soziologie und Sozialpsychologie um, da für sein Soziologieverständnis „Persönlichkeit, Gesellschaft und Kultur“ ein „einheitlicher Zusammenhang“ darstellt, wie es in der Vorbemerkung des neuen Herausgebers 1955 heißt, und mit „Person“ auch eine sozialpsychologische Komponente eminent wichtig wird (vgl. Moebius 2015, S. 59 ff.). Wie König in einem Interview präzisiert, sei aber mit

\footnotetext{
18 Siehe zur Familiensoziologie Schelskys ausführlich Wöhrle (2015, S. 62 ff.), der auch auf dessen widersprüchliche Aussagen zur Rolle der Frau eingeht, ebenso Schäfer (2000, S. 126 f.) sowie Tyrell (1986). 19 Wie seine Leipziger Lehrer Freyer und Gehlen war auch Schelsky nationalsozialistisch aktiv gewesen (vgl. Schäfer 2014, 2015b; Wöhrle 2015, S. 17 ff.).
} 
Sozialpsychologie nicht eine Einzeldisziplin gemeint, sondern die „sozialpsychologische Grundlegung der Soziologie“. (vgl. Neumann und Schäfer 1990, S. 236). Er hat eine Zeitschrift als „universell ausgerichtetes Fachorgan der Soziologie“ vor Augen, in dem auch Nachwuchswissenschaftler zur Sprache kommen sollten (König 1955, S. 1-5).

Durch Königs Herausgeberschaft steigt der Anteil empirischer Arbeiten enorm an. Zusätzlich zur Zeitschrift führt König die Sonderhefte und Schwerpunkthefte ein, die neue Themengebiete erschließen oder wiederbeleben. Kurz nach der Übernahme erschien 1956 das erste Sonderheft zur Soziologie der Gemeinde, dem jedes Jahr ein weiteres folgte (vgl. die Liste im Beitrag von Volker Dreier). ${ }^{20}$ Die Zeitschrift, die bis 1965 auch offizielles Organ der DGS war, avancierte dadurch nicht nur zu einem Eckpfeiler der sogenannten „Kölner Schule“ (vgl. Moebius 2015, S. 111 ff.), sie galt auch international bald als die bedeutendste soziologische Fachzeitschrift im deutschsprachigen Raum. Konkurrenzprojekte sind die seit 1949 erscheinende Soziale Welt und ab Anfang der 1970er-Jahre die Zeitschrift für Soziologie.

Wirft man einen näheren Blick auf die Zeitschriftenaufsätze seit 1955, so kann man bis zum Anfang der 1960er-Jahre unterschiedliche Schwerpunktsetzungen ausmachen (vgl. Lüschen 1979), die sowohl mit den Dynamiken des soziologischen Feldes als auch den gesellschaftlichen Verhältnissen zu tun hatten. Besonders großes Interesse wurde, wie erwähnt, der Industrie-, Gemeinde-, Familien- und Jugendsoziologie sowie Fragen sozialer Schichtung entgegen gebracht (vgl. auch Nolte 2000, S. 267 ff.). Aber auch der Stand der Soziologie und der empirischen Sozialforschung sowie deren Weiterentwicklung und Professionalisierung standen im Fokus. König publizierte 1952 und 1956 seine beiden Bände über Praktische Sozialforschung, die sich mit Interview, Beobachtung und Experiment befassten. 1958 folgte das Fischer-Lexikon, ein soziologischer Bestseller. Seit Anfang der 1960er-Jahre publizierte er das mehrbändige Handbuch der empirischen Sozialforschung. Lüschen (1979, S. 174) charakterisiert in seiner Analyse deutscher Soziologiezeitschriften die frühe Periode ab Mitte der 1950er-Jahre bis 1962 als „Phase teil-theoretischer Diskussionen und sozial-relevanter Empirie“. Schelskys Aufsatz sowie Königs zahlreiche Aktivitäten sind nur wenige Beispiele der Empiriebezogenheit und der methodologischen Diskussionen dieser Zeit. Der hier vorliegende Aufsatz von Gerhard Kleining und Harriett Moore über die „Soziale Selbsteinstufung“ als neues Verfahren zur Messung sozialer Schichten bezeugt das anhaltende Interesse daran und ist ein Beispiel weiterer Professionalisierungsversuche, wobei er auch zeigt, dass man sich seit Mitte der 1960er-Jahre den methodologischen Fragen und Professionalisierungsversuchen nicht bloß abstrakt, sondern vermehrt anhand konkreter Themenund Problemgebiete, wie etwa sozialer Schichten, gewidmet hat.

20 Einzig in den Jahren 1960, 1973, 1985 und 1991 erschien kein Sonderheft. 


\section{Zentrale Kontroversen der bundesrepublikanischen Soziologie in der KZfSS}

$\mathrm{Zu}$ diesen insbesondere die Empirie betreffenden Beiträgen kamen aber seit Ende der 1950er-Jahre auch vermehrt theoretische und wissenschaftstheoretische Debatten hinzu, die eine weitere Ausdifferenzierung und Reflexionsstufe des soziologischen Feldes vor Augen führten. Zwei dieser zentralen Kontroversen der frühen bundesrepublikanischen Soziologie lassen sich im Spiegel der KZfSS beobachten: die Rollendebatte und der Positivismusstreit.

Einer der ersten Highlights und Paukenschläge der Kölner Zeitschrift seit Königs Herausgeberschaft war der hier abgedruckte Text Homo sociologicus von Ralf Dahrendorf aus dem Jahr 1958, ${ }^{21}$ mit dem der erst 29-jährige Dahrendorf die sogenannte Rollendebatte auslöste (vgl. Fischer 2010; Moebius 2016c). ${ }^{22}$ Der Text ist eine Kritik an Talcott Parsons (vgl. Abels 2010, S. $116 \mathrm{ff}$.) und baut auf Dahrendorfs bereits 1955 in der KZfSS publiziertem Beitrag ,Struktur und Funktion. Talcott Parsons und die Entwicklung der soziologischen Theorie“ auf. Dahrendorf kritisiert insbesondere das im Strukturfunktionalismus vertretene Menschen- und Gesellschaftsbild des homo sociologicus, das weder sozialen Wandel noch Konflikte kenne. Er geht aber über eine bloße Parsons-Kritik hinaus, in dem er die Rollentheorie insgesamt angreift. Insbesondere Dahrendorfs These, dass vom „Standpunkt der Gesellschaft und der Soziologie“ „,das Lernen von Rollenerwartungen ein Vorgang [ist], der den Menschen, indem er ihn zum homo sociologicus entfremdet, ihr überhaupt erst zugänglich macht und Bedeutung verschafft" (Dahrendorf 1958, S. 348/189, s. Tab. 1), löste die Debatte aus. „Der rollenlose Mensch ist für Gesellschaft und Soziologie ein nicht existierendes Wesen“ (Dahrendorf 1958, S. 348/189, s. Tab. 1). Dem homo sociologicus, dem soziologischen Blick auf den Menschen als Mitglied der Gesellschaft, der von ihm sogenannten ,ärgerlichen Tatsache der Gesellschaft", stellt Dahrendorf (1958, S. 349/190, s. Tab. 1) den ,ganzen Menschen der Erfahrung“ gegenüber, der immer mehr sei als sein Rollenverhalten (vgl. Abels 2010, S. 131). Er folgt damit eigentlich einem von Georg Simmels soziologischen Apriori, demzufolge der Einzelne in seiner Individualität über seine Vergesellschaftung hinausgeht.

Anstoß an Dahrendorfs Aufsatz wurde zum einen an der schroffen Gegenüberstellung von individueller, gesellschaftsferner Freiheit einerseits und gesellschaftlicher Determiniertheit andererseits genommen und zum anderen an der These von der unentrinnbaren Entfremdung (vgl. Joas 1978, S. 18 ff.). Entdeckte etwa Frigga Haug (1972) in der allgemeinen Entfremdungsthese Dahrendorfs eine typische bürgerliche Ideologie, die nicht mehr zwischen schlechter und guter Gesellschaft unterscheiden könne, so wandte sich König (2002, S. 24) gegen das wechselseitige Ausspielen von

\footnotetext{
21 Im selben Jahr wurde Dahrendorf mit Unterstützung Schelskys Professor in Hamburg an der Akademie für Gemeinwirtschaft.

22 Es ist nicht die erste Kontroverse der BRD-Soziologie: Bereits 1950/51 und in Folge dann 1958/59 fanden andere heftige Kontroversen hinsichtlich der organisationalen Vertretung und Institutionalisierung der Soziologie in Deutschland statt, zwischen DGS und Institut International de Sociologie, die unter der Begrifflichkeit „Bürgerkrieg in der Soziologie“ bekannt sind (vgl. Weyer 1986). Im Folgenden greife ich auf meinen Beitrag über Soziologische Kontroversen nach 1945 (Moebius 2016c) sowie auf Kneer und Moebius (2010) zurïck. Zu Dahrendorfs Text siehe den instruktiven Beitrag von Abels (2010).
} 
Freiheit und Gesellschaft und Individuum und Gesellschaft. Das Individuum werde erst durch das Zusammenleben mit anderen frei. Helmuth Plessner ging in Soziale Rolle und menschliche Natur (1974, S. 30) in eine ähnliche Richtung. Weitere Kritiker in der Kontroverse waren Arnold Gehlen, Helmut Schelsky, Heinrich Popitz, Hans Paul Bahrdt, Dieter Claessens, Friedrich Tenbruck, Peter L. Berger und Thomas Luckmann sowie Hans Peter Dreitzel und Hans Joas (vgl. Fischer 2010, S. 80 f.; zu den einzelnen Argumenten siehe Abels 2010, S. 124 ff.). Keiner von ihnen teilte Dahrendorfs Position. Die Rollendebatte führte aber nicht nur dazu, dass soziologische Klassiker wie Simmel oder Mead innerhalb der deutschsprachigen Soziologie (wieder-)entdeckt wurden oder etwa eine Goffman-Rezeption einsetzte (Fischer 2010, S. 91), sondern sie sorgte auch dafür, ,dass die Soziologie Anfang der 1960erJahre zugleich attraktiv für eine nichtakademische Öffentlichkeit [wurde], weil der Rollenbegriff lebensweltliche Anschlussmöglichkeiten der soziologischen Analytik und des reflektierten gesellschaftlichen ,Rollenspiels“ bietet“" (Fischer 2010, S. 82).

Eine weitere, für die bundesrepublikanische Soziologie zentrale Kontroverse war der Positivismusstreit, der ,zwischen 1962 und 1968 in der Kölner Zeitschrift mit Beiträgen von Hans Albert, Jürgen Habermas, Harald Pilot und K.R. Popper ausgetragen und erst danach durch Theodor W. Adorno mit Ergänzungen als selbstständiges Buch“ (Lüschen 1979, S. 171) publiziert wurde. Karl Poppers im vorliegenden Heft abgedrucktes Referat „Die Logik der Sozialwissenschaften“, gehalten auf einer internen Arbeitstagung der DGS 1961 in Tübingen, bildete den Startpunkt der Auseinandersetzung. Diese reichte jedoch im Grunde bis zu Kontroversen zwischen Frankfurter Schule und logischen Positivisten des Wiener Kreises in die 1930er und 1940er-Jahre zurück (vgl. Dahms 1994).

Ziel des Tübinger Arbeitstreffens war es gewesen, die Meinungsverschiedenheiten innerhalb der DGS auszudiskutieren und durch ,eine wissenschaftstheoretische Diskussion zu objektivieren“ (Lepsius 1979, S. 43). Im Streit selber ging es weniger um den Positivismus im eigentlichen Sinne, zu dem auch nicht Popper gezählt werden kann (Dahms 1994, S. 332 ff.; Ritsert 2010, S. 107), der sich sogar explizit kritisch gegenüber dem Positivismus äußerte, sondern vielmehr um grundsätzliche wissenschaftstheoretische und Werturteilsfragen.

Die Positionen zwischen Adorno und Popper lagen nicht so weit auseinander, einig war man sich in der Ablehnung des Szientismus der Kölner Schule und der Wissenssoziologie Mannheims. Zum eigentlichen Streit kam es dann erst durch Adornos überproportional lange Einleitung in dem 1969 erschienenen Sammelband und die „Wiederbelebung der ,Popper-Legende“"“, die diesem doch eine Nähe zum Positivismus nachzusagen versuchte, ,,mit der Nuance [...], er sei auch in politischer Hinsicht ein ,Posivitist“, also jemand, der ,das Bestehende“ (den gesellschaftlichen Status quo) verteidigt" (Dahms 2008, S. 32 f.).

Scheuch, der 1961 mit seiner Wahlstudie große Aufmerksamkeit auf sich zog und daraufhin die Methodensektion der DGS gründete (vgl. Moebius 2015, S. 89), mischt sich mit dem im vorliegenden Heft abgedruckten Aufsatz ,Sozialer Wandel und Sozialforschung“" von der Kölner Seite in den Positivismusstreit mit ein. Er erörtert anhand eines Deutschland-USA-Vergleichs ausdrücklich die Beziehungen zwischen Gesellschaft und empirischer Sozialforschung, die als „Folge und Agens sozialen Wandels“ (Scheuch 1965, S. 2/245, s. Tab. 1) auftreten kann. So sei sie 
gerade nicht, wie manche ihrer Kritiker von links oder rechts meinten, ein Instrument des Konformismus oder der Aufrechterhaltung des Status quo, sondern ein Mittel der Rationalisierung und des kritischen Wandels. Das erinnerte nicht nur an Königs Position, sondern darüber hinaus an Émile Durkheims Glauben an eine methodisch rationalisierte kritische Gesellschaftswissenschaft. Darum nimmt es nicht Wunder, dass auch Durkheim zum „Spieleinsatz“ in den Auseinandersetzungen im soziologischen Feld wurde, wie in Adornos hier vorliegender ,Notiz über sozialwissenschaftliche Objektivität" (1965) deutlich wird, in der er Durkheim als affirmativen Ideologen kritisiert; kritische Gesellschaftstheorie würde bei diesem durch ordnende Begriffsschemata substituiert. Der Angriff galt indirekt auch Königs „Begründung einer objektiven Soziologie“" (so der Untertitel von Königs Habilitationsschrift) und bildete den Auftakt einer allgemeinen Abrechnung mit Durkheim seitens Adornos: 1967 versuchte Adorno in der Einleitung zur Durkheim-Textsammlung Soziologie und Philosophie mit Durkheim auch zugleich König zu demontieren (vgl. Peter 2013), was sogar soweit ging, dass Adorno den Reformsozialisten und Moralisten Durkheim in die Nähe faschistischer Ideologen rückte. König erkannte dieses diskurspolitische Manöver und reagierte in seinen Durkheim-Interpretationen mit einer sorgfältigen Korrektur der Fehllektüre Adornos.

Die erwähnten Kontroversen waren zentrale Momente eines Konsolidierungs- und eines „Selbstverständigungsprozesses in der deutschen Soziologie“ (Schmid 2004, S. 24). Sie bestimmten einen guten Teil der Diskussionen der nächsten Jahrzehnte und mündeten über die Kontroverse „Spätkapitalismus oder Industriegesellschaft“ und die „Habermas-Luhmann-Debatte“ in die „Theorievergleichsdebatte“ Mitte der 1970er-Jahre (vgl. Kneer und Moebius 2010; Moebius 2016c), deren Wirkungen sich bis in die Gegenwart beobachten lassen (vgl. Greshoff 2010, S. 210 ff.).

Die Kontroversen, die den Verlauf der bundesrepublikanischen Soziologie wesentlich prägten, sollten jedoch nicht den Blick auf andere Gegenstände und gesellschaftliche Problemlagen verstellen. Im Übergang zu den 1960er-Jahren waren sozialer Wandel, Mobilität und soziale Schichtung zentrale Angelegenheiten soziologischer Forschung (vgl. Lüschen 1979, S. 191, FN. 29; Nolte 2000, S. 267). Wie Lüschens Analyse und auch die Titel der Sonderhefte der KZfSS zeigen (vgl. Lüschen 1979, S. 181, Tab. 2; Dreier 2016, S. 12, Anhang 1), folgten in den Jahren darauf schwerpunktmäßig Themen wie Soziologie der Politik (ausgelöst durch die Notstandsgesetze und „1968“), Wirtschaft, Organisation, Kunst, Bildung, Wissen, Entwicklungssoziologie, Soziologische Theorie und damit verbunden die Wiederentdeckung der Klassiker (vgl. Nolte 2000, S. 268). Für Politik als große soziologische Problemstellung der 1970er-Jahre steht hier beispielhaft Ulrich Becks und Elisabeth Gernsheims vorliegender Aufsatz zu den „Studentenunruhen“, den man in den Kontext einer „kulturellen Neuorientierung“ der jüngeren Generation in den Sozialwissenschaften stellen kann (vgl. Nolte 2000, S. 268), für die bereits Ralf Dahrendorf stand und die sich nach Nolte (2000, S. 268) mit folgenden Schlagworten benennen lässt: Aufgabe der Sehnsucht nach Harmonie und Integration, Anerkennung der gesellschaftlichen Konflikte, Dynamiken und der ,permanenten Austragung von Interessengegensätzen“" 


\section{Wiederentdeckung der Klassiker und die Etablierung neuer (Theorie-)Positionen im soziologischen Feld}

Für die Wiederentdeckung der Klassiker stehen nicht nur die Durkheim-Rezeption Königs oder die Marx-Renaissance der 1960er-Jahre, sondern auch Friedrich Tenbrucks legendäre Max Weber-Aufsätze, von denen einer in diesem Sonderheft abgedruckt ist. Tenbruck stellt besonders Webers Rationalisierungsthese in den Mittelpunkt der Werkinterpretation und erweitert damit insgesamt die Rezeption Webers. Denn zusammen mit anderen Texten Tenbrucks, die dieser bereits in den 1950erJahren vorgelegt hatte, führte seine Kritik, Wirtschaft und Gesellschaft sei nicht das Hauptwerk Webers, zu einer anderen Sicht auf Webers Soziologie und schließlich zu einer neuen historisch-kritischen Gesamtausgabe (vgl. Homann 1999, S. XVIII). Bereits zehn Jahre vor Tenbrucks Aufsatz hatte in Heidelberg ein Soziologentag zu Weber stattgefunden, der aber noch wenig Resonanz ausgelöst hatte (vgl. Lüschen 1979, S. 175). Hingegen wurde Weber vermittelt durch Tenbrucks Rezeption einer der wichtigsten Klassiker für die Wiederbelebung der deutschen Kultursoziologie Ende der 1970er-Jahre (vgl. Moebius und Albrecht 2014).

Das Bedürfnis nach neuen Impulsen, die man sich von den Klassikern erhoffte, ist sowohl gesellschaftlichen Prozessen der Rationalisierung, funktionaler Differenzierung, sozialer Desintegration und daraus resultierender neuer Konflikte und Problemwahrnehmungen geschuldet als auch ein Resultat der Unzufriedenheit mit bestehenden Theorieangeboten, diese Prozesse adäquat zu erfassen. Kritik wurde insbesondere an dem als hegemonial wahrgenommenen Strukturfunktionalismus Parsons laut. Ein Beispiel dafür ist die Neuetablierung der Kultursoziologie, die wie erwähnt seit Ende der 1970er-Jahre in ihrer Hinwendung zu Weber und Abwendung von Parsons, Marxismus und Rollentheorie eine Renaissance erlebte (Moebius und Albrecht 2014). Aber auch die zunehmende Theorienvielfalt, wie sie etwa in der Theorienvergleichsdebatte Mitte der 1970er-Jahre zum Ausdruck gekommen war (vgl. Greshoff 2010), wurde immer offensichtlicher nicht als positives Zeichen einer reifen Disziplin, sondern eher als unfruchtbar wahrgenommen. Ein aus der Theorienvielfalt resultierendes Bedürfnis nach neuen Synthesen (und neuen Positionierungen im soziologischen Feld) kam in Auseinandersetzung mit den Klassikern und mit Parsons zum Ausdruck (vgl. Joas und Knöbl 2004, S. 285 und S. 351). Es ist insbesondere an die grand theories von Jürgen Habermas (1981) und Niklas Luhmanns Systemtheorie zu denken, die sich bereits in den 1960er und 1970erJahren zu entwickeln begannen und Anfang der 1970er-Jahre in der Habermas-Luhmann-Debatte aufeinander trafen. In dem hier vorliegenden Aufsatz Luhmanns, in dem ein systemtheoretisches Verständnis von Handlung entwickelt wird, tritt dessen differenzierte Auseinandersetzung mit Parsons, die Ablehnung Parsonsianischer Handlungstheorie bei gleichzeitiger Rezeption seiner Systemtheorie (vgl. auch Joas und Knöbl 2004, S. 355), eindrucksvoll vor Augen.

Auch die Wiederentdeckung Norbert Elias' steht im Zeichen solcher Neuorientierungen im soziologischen Feld und ist Rehbergs (1979, S. 113 ff.) ausführlicher Rezeptionsanalyse zufolge nur vor dem Hintergrund der Marx-Renaissance und der „nach-Marx’schen Diskussionen“ (Rehberg 1979, S. 118) zu verstehen: Elias' Zivilisationstheorie, ,versöhnlicher“ als der Marxismus, avancierte zum „Refugium“ 
und „Medium des Überlebens historisch-materialistischer Kritik“ (Rehberg 1979, S. 122); sie war somit offener für Anschlussmöglichkeiten aus unterschiedlichen theoretischen und politischen Lagern.

Wie man an der wieder auflebenden Kultursoziologie oder auch an der Elias-Rezeption sehen kann, verbanden sich mit der Wiederentdeckung der Klassiker vielfach neue Gruppenbildungen und Positionierungsbestrebungen im soziologischen Feld. Damit einher gingen erneute Synthese- und Distinktionsversuche. Hartmut Essers vorliegender Elias-Aufsatz ist in einem solchen Kontext zu sehen, der die Übereinstimmungen und Affinitäten zwischen Elias' Figurationssoziologie (FS) und dem von Esser favorisierten analytischen Wissenschaftsverständnis sowie der Konzeption des Methodologischen Individualismus (MI) auslotet, und sich bewusst darüber ist, dass seine Auffassung von der ,,inzwischen ja gut etablierten Elias-Gemeinde zurückgewiesen werden wird“ (Esser 1984, FN 2/S. 457, s. Tab. 1). Nachdem er Affinitäten zwischen FS und MI aufgezeigt hat, sind für ihn schließlich angesichts der frappierenden Gemeinsamkeiten zwischen FS und MI eher die Distinktionspraktiken der Figurationssoziologen gegenüber dem MI erklärungsbedürftig (Esser 1984, S. 695/489, s. Tab. 1). Warum beanspruche die Figurationssoziologie (FS) eine Eigenständigkeit ihrer Soziologieauffassung, erweise sie sich doch, so Esser, in ihren Orientierungshypothesen absolut vereinbar mit dem MI? Allerdings ist umgekehrt ebenso der theoriestrategische Eingemeindungsversuch Essers erklärungsbedürftig und vielleicht einer detaillierteren feldsoziologischen Analyse wert.

\section{1980er-Jahre}

Nach seiner Emeritierung 1974 gab König seit 1977 die KZfSS mit seinem Nachfolger Friedhelm Neidhardt heraus. ${ }^{23} 1979$ kam als Dritter in das Herausgebergremium Christian Ludz hinzu, der allerdings im selben Jahr verstarb. An seine Stelle trat M. Rainer Lepsius (bis 1996). König schied 1985 aus dem Herausgebergremium aus. Esser war von 1987-1991 Mitherausgeber. Langjähriger Redakteur (von 1977-2006) war Heine von Alemann. ${ }^{24}$ Ende der 1980er-Jahre wurde ein wissenschaftlicher Beirat eingeführt mit zunächst fünf, seit 1990 sieben Personen (vgl. Friedrichs et al. 1997, S. VIII; Dreier 2016, S. 6). Friedhelm Neidhardt blieb bis 1992 geschäftsführender Herausgeber, es folgte dann bis 2013 Jürgen Friedrichs. ${ }^{25}$

Die bis heute anhaltende Produktivität der Zeitschrift zeigte sich auch an ihren Sonderheften, von denen nahezu jedes Jahr eines erschien. Die Rückbesinnung auf die Geschichte der Soziologie, von der oben bereits die Rede war, kam in den Sonderheften zur Deutschen Soziologie nach 1945 (Lüschen 1979, Sonderheft 21) ${ }^{26}$

\footnotetext{
23 Von 1972-1980 waren Günter Albrecht, Fritz Sack und Alphons Silbermann an der Herausgabe beteiligt, traten aber nicht offiziell als Mitherausgeber auf.

24 Frühere Redakteure waren: Peter Heintz, Dietrich Rüschemeyer, Fritz Sack, Karl-Dieter Opp, Günter Albrecht, Axel Schmalfuß; seit 2006 ist Volker Dreier Redakteur.

25 Von 2013 bis 2015 war dann Karsten Hank GfH der KZfSS, seit 2016 ist es Hans-Jürgen Andreß.

26 An dieses Sonderheft schloss sich eine weitere Kontroverse an, eine über die Geschichte der Soziologie, die insbesondere zwischen Lepsius und König auf der einen Seite und Schelsky auf der anderen Seite verlief und über die Frage ging, ob die Soziologie bereits vor 1933 an ihr Ende gekommen war (Schelsky)
} 
sowie in dem 1981 publizierten Sonderheft 23 zu Soziologie in Deutschland und Österreich 1918-1945 (Lepsius 1981) zum Ausdruck. Für eine soziologiehistorische Analyse der Geschichte der Soziologie im Spiegel der KZfSS sind auch die Gegenstandsbereiche der Sonderhefte in den 1980er-Jahren interessant. Bearbeitet wurden Wirtschaft, Industriesoziologie, Massenkommunikation, Wissenssoziologie, die Bundesrepublik befand sich in einem wirtschaftlichen Übergang von der Industrie- zur Dienstleistungsgesellschaft, der Bildungsbereich wuchs an, weitere Themen waren Ethnologie, Kultur und Gesellschaft, Stadtforschung, Organisationssoziologie, Gruppensoziologie sowie Lebensverläufe und sozialer Wandel.

Für die letztgenannten Themen beispielhaft sind die hier vorliegenden Beiträge von Friedhelm Neidhardt zur Gruppensoziologie, von Wolfgang Streeck zum Wandel intermediärer Organisationen und von Martin Kohli zur Lebenslaufanalyse. Kohlis Beitrag hebt die Notwendigkeit hervor, „Lebenslauf und Lebensalter als eine eigenständige gesellschaftliche Strukturdimension aufzufassen“ (Kohli 1985, S. 1/495, s. Tab. 1). Im selben Jahr, in dem sein Aufsatz erschien, gründete er an der FU Berlin die Forschungsgruppe Altern und Lebenslauf (FALL). Dabei korrespondierte das steigende soziologische Interesse an Lebensalter und Lebensverlauf mit den zeitgenössischen demografischen Prozessen eines Geburtenrückgangs, einer zunehmenden Alterung und Individualisierung der Gesellschaft (vgl. Conze 2009, S. 546 ff.) sowie den Emanzipationsprozessen von Frauen.

Neidhardt betont im vorliegenden Aufsatz, „Gruppe“ als soziologische (und nicht nur sozialpsychologische) Kategorie zu entwickeln. Gab es zuvor auch bereits gruppensoziologische Forschungen und Ansätze, wie sie etwa König in einem Artikel seines berühmten Fischer-Lexikon seitenlang aufführt, so mangelte es jedoch vielfach an einer systematischen Präzision dessen, wie „Gruppe“ als analytische Kategorie in der Soziologie und in Distinktion zum Gruppenbegriff in der Sozialpsychologie bestimmt werden könnte. In Neidhardts Augen kann die soziologische Spezifizität der Kategorie „Gruppe“ am besten mit einer systemtheoretischen Herangehensweise herausgearbeitet werden, wenn Gruppe weniger funktional, sondern vielmehr als System persönlicher Beziehungen und als ein spezifischer ,Sinnzusammenhang von Handlungen“" (Neidhardt 1979, S. 641/436, s. Tab. 1), angesiedelt zwischen einfachen Systemen und Organisationen, definiert wird. Die Gruppensoziologie war bedeutsam für Neidhardts Soziologie terroristischer Vereinigungen und Handlungsprozesse, seine Expertise und gruppensoziologischen Forschungen über die BaaderMeinhof-Gruppe (Neidhardt 1982a, b) erhielten auch für die Terrorismusbekämpfung des BKA unmittelbare Relevanz. 1983 gab Neidhardt ein eigenes Sonderheft der KZfSS zur Gruppensoziologie heraus.

Streecks Beitrag befasst sich mit den Wandlungsprozessen ,sekundärer Systeme“ (Streeck 1987, S. 472/526, s. Tab. 1), den intermediären Organisationen, also mit Gebilden, wie er schreibt, die ,sowohl Mitglieder haben als auch Mitglieder sind“" (Streeck 1987, S. 472/526, s. Tab. 1), respektive Parteien, Gewerkschaften, Verbände, Vereine, neue soziale Bewegungen. Bereits wenige Jahre zuvor hatte er über den

oder ob sie gerade gegen Ende der Weimarer Republik eine fundamentale Belebung erfahren hat, die dann „brutal zum völligen Stillstand gebracht“ worden sei (König 1967 [1958], S. 14, 1987, S. 343 ff.; Lepsius 1979, S. 26, 1981a, S. 17; Schelsky 1981, S. 15). 
organisatorischen Wandel deutscher Gewerkschaften geforscht. Streecks Gewerkschaftsforschung vollzog sich vor dem Hintergrund eines Wandels der Gewerkschaften, deren korporatistische Funktion im „,deutschen Kapitalismus“ der fordistischen Phase von einem weltmarktorientierten „Wettbewerbskorporatismus“ abgelöst wurde, was eine Deregulierung von Arbeitsbeziehungen, Lohnverzicht und schwindende gewerkschaftliche Konfliktfähigkeit zur Folge hatte.

Der vorliegende Aufsatz vertieft Streecks Neo-Korporatismusforschungen, er verknüpft die Frage nach dem Wandel der intermediären Organisationen aufgrund sich verändernder Umweltbedingungen mit dem Aufweis neuer Forschungsperspektiven. Wie erklärt sich beispielsweise die Zunahme der Dienstleistungsorientierung intermediärer Organisationen? Inwieweit verlieren Gewerkschaften oder andere Interessensverbände aufgrund staatlicher Deregulierungspolitik immer mehr an Einfluss (vgl. Streeck 2008, S. 657)? Es gilt für die Organisationen insbesondere zwischen zwei Ebenen zu vermitteln, zwischen Sozialintegration nach innen und Systemintegration nach außen und zwischen „Mitglieder- und Einflußlogik“ (Streeck 1987, S. 474/528, s. Tab. 1), wobei die ,Zwischenstellung“ der intermediären Organisationen zwischen der Mikro- und der Makroebene sowie „mögliche Interaktionseffekte" und Wechselwirkungen zwischen beiden zu berücksichtigen sind (Streeck 1987, S. 491/545, s. Tab. 1). Die Frage der Überwindung des Mikro-Makro-Dualismus sollte dann gegen Ende der 1980er-Jahre auch für das soziologietheoretische Feld zentral werden.

\section{Dynamiken im soziologietheoretischen Feld in den 1980er-Jahren}

Überhaupt waren die 1980er-Jahre für die bundesdeutsche Soziologie insbesondere mit Blick auf die Prozesse im soziologischen Theoriefeld bedeutsam. Pointiert könnte man sagen, es war eine Blütezeit ,großer“ soziologischer Theorien: 1981 erschien Jürgen Habermas’ Theorie des kommunikativen Handelns, 1984 Niklas Luhmanns Soziale Systeme. Grundriß einer allgemeinen Theorie [83]. Der PostmoderneDiskurs kam von Frankreich und den USA nach Deutschland, wo postmoderne und poststrukturalistische Konzepte heftig bekämpft wurden (Kneer und Moebius 2010). 1984 erschien der zweite Band von Thomas Luckmanns und Alfred Schütz' Strukturen der Lebenswelt. 1986, zeitgleich mit der Reaktorkatastrophe von Tschernobyl, erschien Ulrich Becks Risikogesellschaft und legte den Grundstein für die Theorie reflexiver Modernisierung. Im soziologietheoretischen Feld fand darüber hinaus eine „Erneuerung des Parsonianismus“ (Joas und Knöbl 2004, S. 430 ff.) statt, im deutschsprachigen Raum insbesondere repräsentiert durch die Arbeiten von Richard Münch. Verstärkt wurden auch andere internationale Theorien rezipiert, so etwa der amerikanische Pragmatismus, dessen soziologische Aspekte insbesondere Hans Joas weiter entwickelte, die Praxistheorien von Pierre Bourdieu und Anthony Giddens sowie neo-institutionalistische Ansätze und Rational-Choice-Theorien. Verdeutlichten Habermas und Luhmann zu Beginn der 1980er-Jahre noch einen Dualismus zwischen Handlung/Akteur und Struktur/System, so wurden gegen Ende der 1980erJahre mit Elias, Bourdieu und Giddens Ansätze zur Überwindung dieses Dualismus aufgegriffen und diskutiert. Die Überwindung des Dualismus und die enge Verknüp- 
fung zwischen Mikro- und Makro-Perspektive ist nach Jeffrey Alexanders (1988) Einschätzung international das Kennzeichen zeitgenössischer Theorieentwicklungen und -bestrebungen der jüngeren Generation der 1980er-Jahre. Ein Beispiel für ein solches „synthetisches Theoretisieren“ (Alexander 1988, S. 77) ist der Aufsatz von Uwe Schimank in diesem Heft, dessen akteurbasierte Differenzierungstheorie ,akteurstheoretische Erklärungen gesellschaftlichen Handelns durch Einbau des systemtheoretischen Konzepts des gesellschaftlichen Teilsystems zu verbessern“" trachtet (Schimank 1988, S. 620/550, s. Tab. 1).

\section{Gesellschaft und Soziologie nach 1990}

Mit dem Mauerfall gerieten die in den 1980er-Jahren zu beobachtenden politischen Probleme der Bundesrepublik, wie beispielsweise die steigende Arbeitslosigkeit, für kurze Zeit in den Hintergrund; die bereits deutlich bemerkbare „Europäisierung nationaler Gesellschaften“ (siehe Bach 2000) und der allgemeine Globalisierungsprozess erfuhren einen wesentlichen Beschleunigungsschub (Schild und Siegfried 2009, S. 444 f.), der gleichzeitig Reaktionen regionalistischer, nationalistischer und identitärer Kräfte hervorrief. Auch wenn der Mauerfall und die Wiedervereinigung ebenso wenig eine Art „Stunde Null“ darstellten wie das Jahr 1945 (vgl. Rehberg 2000, S. 20), so bedeuteten sie dennoch einen enormen Umbruch. Angestoßen durch den von den Sozialwissenschaften nicht vorhergesehenen gesellschaftlichen Wandel machten sich in den Sozialwissenschaften neue Prozesse und Impulse bemerkbar (vgl. Krause und Ostner 2010). So begann relativ schnell eine soziologische Transformationsforschung einzusetzen (vgl. Hauser 2010), nicht zuletzt vorangetrieben durch die Gründung einer ,Kommission für die Erforschung des sozialen und politischen Wandels in den neuen Bundesländern“ (KSPW), deren Aufgaben mit der Umorganisation des ostdeutschen Wissenschaftssystems zusammenhing, und der „Einrichtung eines Schwerpunktprogramms der Deutschen Forschungsgemeinschaft“ mit dem Titel ,Sozialer und politischer Wandel im Zuge der Integration der DDR-Gesellschaft", das bereits im Juni 1990 von Klaus Allerbeck, Hartmut Esser, Karl Ulrich Mayer, Werner Tack und Erwin K. Scheuch initiiert und Anfang 1991 von der DFG bewilligt wurde (Esser 2000, S. 7 f.).

In der soziologischen Transformationsforschung ließen sich unterschiedliche Sichtweisen beobachten (vgl. Joas und Kohli 1993; Schäfers 1996; Conze 2009, S. 749; Krause und Ostner 2010), die Palette an Ansätzen reichte von modernisierungstheoretischen (etwa vertreten von Wolfgang Zapf 1991a, 1991b), systemtheoretischen (vertreten beispielsweise von Detlef Pollack 1990a, 1990b), institutionenund mentalitätssoziologischen (Wolfgang Schluchter 1996), rechtssoziologischen (Bernhard Schäfers 1996), geschlechtersoziologischen (beispielsweise die Untersuchungen von Hildegard Nickel 1995), bewegungssoziologischen (Wiehlgohs und Schulz 1993) bis hin zu individualistischen oder akteurstheoretischen RationalChoice-Ansätzen (repräsentiert etwa durch Karl-Dieter Opp, dessen Aufsatz zum Thema im vorliegenden Heft abgedruckt ist.).

Kennzeichnend für die 1990er-Jahre waren auf der Ebene der gesellschaftlichen Wandlungsprozesse neue soziale Problemlagen, denen auf der Ebene des soziolo- 
gischen Feldes eine Zunahme der Bedeutung an Speziellen Soziologien korrespondierte (bei gleichzeitiger Abnahme der Rezeption der soziologischen grand theories von Habermas und Luhmann).

Die von Helmut Kohl im Wahlkampf versprochenen und die Erwartungen an ein erneutes Wirtschafswunder beflügelnden „blühenden Landschaften“ blieben aus. Das bereits vor 1990 vorherrschende Problem struktureller Arbeitslosigkeit, deren Ursache auch in der ökonomischen Globalisierung (vgl. Görtemaker 2009, S. 101 ff.) lag, wurde durch die Wiedervereinigung verstärkt. Gesellschaftliche Spaltungs- und Desintegrationsprozesse nahmen zu (vgl. Honneth 1994; Heitmeyer 1997; Lessenich und Nullmeier 2006).

„Soziologen, die in den 80er-Jahren Konzepte einer, differenziert-pluralen Nachklassengesellschaft " vorgestellt hatten, wurde nun auch von nichtmarxistischer Seite eine ,ideologieträchtige Blickverengung ' attestiert. Auch der Begriff der ,Armut" und vor allem der ,Kinderarmut ' erhielt verstärkte öffentliche Aufmerksamkeit - nachdem er in den Sozialwissenschaften bereits seit den 80er-Jahren diskutiert worden war" (Schildt und Siegfried 2009, S. 481 f.; vgl. auch Honneth 1994, S. 100 ff.).

Das Sonderheft 32 der Kölner Zeitschrift für Soziologie und Sozialpsychologie $(K Z f S S)$ mag als Indiz und Reaktion gelten, es widmete sich 1992 der „Armut im modernen Wohlfahrtsstaat“" (Leibfried und Voges 1992). „Armut trotz Wohlstand“ (Bohle 1997), das war ein Befund, der in seiner paradoxen Form eingehende soziologische Analysen auf den Plan rief. Dementsprechend nahmen die soziologischen Forschungen zu Prekarität, sozialer Exklusion und „Exklusionsempfinden“ seit den 1990er-Jahren zu (vgl. Schildt und Siegfried 2009, S. 482; Bude und Willisch 2007).

Bei der Mehrzahl der Ostdeutschen machten sich bald nach der „Vereinigungseuphorie" Gefühle der Fremdbestimmung, der Heimatlosigkeit, der Ernüchterung, der „kulturellen Abwertung“ (Conze 2009, S. 748) und der ,diffusen Ängste“ breit, wie sie beispielsweise der ehemalige Präsident des deutschen Bundestags Wolfgang Thierse beobachtete:

„Das staatlich vereinigte Deutschland ist heute ein von Ängsten bedrängtes, von Ungleichheiten und Ungleichzeitigkeiten geprägtes Land! [...] Diese marodierenden Ängste verdichten sich wechselnd zur Angst vor Arbeitslosigkeit, vor Kriminalität, vor ,Überfremdung', vor kriegerischen Verwicklungen Deutschlands. Sie suchen immer wieder neue und immer wieder dieselben Objekte der Aggressionsabführung: Asylbewerber, Ausländer, Fremde, Behinderte, Linke, Minderheiten generell (und auch - als unspezifische Objekte von Verdrossenheit - ,die Politiker')“ (Thierse 1994, S. 53 f.).

Die Zahl der rechtsextremistischen Gewalttaten sowie der Grad der Zustimmung zu ihnen stieg seit 1991 immens an (vgl. Conze 2009, S. 784 ff.). Die „Aggressionsabführungen“, wie Thierse schreibt, sowie die Desintegrationsängste waren (und sind) aber nicht nur ein Resultat der Wende oder allein auf Ostdeutschland beschränkt, auch wenn sie hier aufgrund von massiven Desintegrationsprozessen, Demokratiekritik, Benachteiligung(sgefühlen) und sozio-ökonomischen Defiziten „,stärker ausgeprägt" waren (Babka von Gostomski et al. 2007, S. 121; Mansel und Kaletta 2009). Dass sie auch strukturell bedingter Ausdruck von, durch Einführung von Hartz IV (seit Anfang 2005) verstärkten, sozialen Abstiegsängsten, neolibera- 
len Globalisierungstendenzen und damit zusammenhängenden Renationalisierungsund Identitätspolitiken waren (erinnert sei etwa an die Debatten um „Leitkultur“ in Deutschland (vgl. Schildt und Siegfried 2009, S. 513), „DM-Nationalismus“ (so Habermas), an den Rechtspopulismus von Jörg Haider in Österreich oder an Berlusconi in Italien (vgl. Conze 2009, S. 825), zeigten die empirischen Studien zur ,gruppenbezogenen Menschenfeindlichkeit" der Forschergruppe um Wilhelm Heitmeyer. ${ }^{27}$

Zu gesellschaftsrelevanten Themen avancierte außerdem der Umweltschutz. 1996 veröffentlichten Andreas Diekmann und Carlo J. Jaeger das Sonderheft der KZfSS zur Umweltsoziologie. Es ließen sich mit Blick auf das Umweltverhalten erhebliche Diskrepanzen zwischen Anspruch und Wirklichkeit ökologischen Handelns nicht nur auf politischer, sondern wie der Beitrag von Andreas Diekmann und Peter Preisendörfer im vorliegenden Heft zeigt, auch auf der individuellen Verhaltensebene ausmachen. Die Widersprüche zwischen Umweltbewusstsein und individuellem Verhalten, die bei den Akteuren oft mit bestimmten rationalen, ihr ambivalentes Verhalten rechtfertigenden Diskursstrategien zur Aufhebung der Widersprüche kognitiv bewältigt werden, lassen sich der rationalitätstheoretischen Annahme der Autoren zufolge ansatzweise durch eine ,Kombination von Umweltbewusstsein und individuellen Anreizen“ lösen.

Ein weiteres gesellschaftsrelevantes Thema war die Bildungspolitik und das Bildungssystem, das insbesondere Mitte der 2000er-Jahre verstärkt in den Fokus der politischen und gesellschaftlichen Aufmerksamkeit rückte. Wissenschaft und Bildung wurden nun vermehrt unter dem Blickwinkel ihrer unmittelbaren Verwertbarkeit betrachtet. Dazu trugen insbesondere die PISA-Tests (Programme for International Student Assessment) bei. Die PISA-Tests offenbarten in Deutschland und im Vergleich zu anderen Ländern Bildungsdefizite sowie ungleich verteilte Chancen, alle Bevölkerungsgruppen an der Bildungsexpansion teilhaben zu lassen (vgl. Wolfrum 2013, S. 511). Besonders die in der Bildungssoziologie bereits seit den 1970er-Jahren von Pierre Bourdieu und Jean-Claude Passeron (1971) ausgemachte Korrelation zwischen sozialer Herkunft, kulturellem Kapital und schulischer Leistung bestätigte sich. Auch in Deutschland konnten Bourdieus und Passerons Ergebnisse bereits viele Jahre vor PISA bestätigt werden, wie der vorliegende Beitrag von Richard D. Alba, Johann Handl und Walter Müller aus dem Jahr 1994 zeigt. Wie anhand der Analyse der Benachteiligungen unterschiedlicher Einwanderergruppen im Schulsystem deutlich wird, beruht ,ethnische Ungleichheit im deutschen Bildungssystem“ nicht nur auf der unterschiedlichen Verfügung über ökonomisches Kapital als vielmehr auf ,kulturellen Faktoren wie die im Elternhaus gesprochene Sprache und die Schullaufbahn des Kindes“ (Alba et al. 1994, S. 235/642, s. Tab. 1). Dass sich diese Ungleichheiten so lange halten und bis heute in den PISA-Tests offensichtlich werden, deutet daraufhin, dass sozialstrukturelle Unterschiede und Ungleichheiten nicht durchlässiger oder entstrukturierter geworden sind, sondern sich weiterhin reproduzieren (vgl. Lessenich und Nullmeier 2006). Ein solches Ergebnis zeigen nicht nur an Bourdieu angelehnte Studien (Schultheis und Schulz 2005), zu diesem Ergebnis kommt beispielsweise auch die hier abgedruckte Studie von Hans-Peter Blossfeld

27 All diese Prozesse sind natürlich auch im Kontext globaler Krisen zu sehen, man denke an den IrakKrieg, den Bürgerkrieg in Jugoslawien oder die Auflösung der UDSSR (vgl. Herbert 2014, S. 1144). 
und Andreas Timm zum „Einfluss des Bildungssystems auf den Heiratsmarkt“: „Die Entwicklung der Bildungshomogamiequoten über die Kohorten hinweg spricht [...] für eine zunehmende Schließung der Sozialstruktur und sozialen Kreise. [...] Das heißt, die intragenerationale und intergenerationale Reproduktion sozialer Ungleichheit setzt sich in der Regel hinter dem Rücken der Individuen durch, und es stellt sich die Frage nach dem soziologischen Wert von empirischen Studien, die sich zu sehr auf individuelle Präferenzen stützen“ (Blossfeld und Timm 1997, S. 471/677, s. Tab. 1).

Nicht unerwähnt sollten neben Arbeitslosigkeit, Prekarität, Armut, Xenophobie, Exklusion, Umweltschutz, Migration und Bildung auch andere Prozesse und soziale Problemlagen bleiben, die seit den 1990er-Jahren gesellschaftlich und soziologisch relevant wurden, hier aber nur stichwortartig und nicht erschöpfend aufgelistet werden können. Infolge der Terroranschläge des 11. September 2001 kam es zu einem Boom der Religions- und Kultursoziologie. Insbesondere wegen der Finanzkrise 2008 erlebten wirtschaftssoziologische und kapitalismustheoretische Analysen einen Aufschwung (siehe auch die Sonderhefte 45, Windolf 2005 sowie 49 der KZfSS, Beckert und Deutschmann 2009). Zwischenzeitlich hatten raum- und stadtsoziologische Forschungen Hochkonjunktur, weiterhin spielen aufgrund anhaltender geschlechtsspezifischer Benachteiligungen und Sexismus geschlechtersoziologische Studien eine zentrale Rolle, außerdem Studien zu Individualisierung und neuen Vergemeinschaftungsprozessen sowie den steigenden, gesellschaftlich vermittelten Selbstoptimierungsanforderungen an die Individuen (Gouvernementalitätsforschungen). Aktuelle soziologische Zeitdiagnosen sprechen von Angst- (Bude 2014) und Abstiegsgesellschaften (Nachtwey 2016).

\section{Soziologie und intellektuelle Kritik}

All diese Prozesse und Problemlagen verlangen nach soziologischer Analyse und Kritik. Sie verweisen insofern auf den Aufsatz von M. Rainer Lepsius (1964, S. $75 \mathrm{ff} . / \mathrm{S} .229 \mathrm{ff} .$, s. Tab. 1) zur „Soziologie der Intellektuellen“ im vorliegenden Sonderheft, weil sie auch die Frage nach der Rolle der Soziologinnen und Soziologen als Intellektuelle innerhalb (und nicht freischwebend) der von ihnen analysierten gesellschaftlichen Verhältnisse aufwerfen. Dürfen Soziologinnen und Soziologen die Rolle von Intellektuellen einnehmen, dürfen sie als kompetente, professionelle Beobachter und Analytiker der Gesellschaft soziale Problemlagen nicht nur beobachten, messen und beschreiben, sondern auch kritisieren, (Gesellschafts-)Kritik zu ihrem Beruf oder ihrer Berufung machen (vgl. Moebius und Schäfer 2006; Peter 2016)?

Der Text von Lepsius ist eine erweiterte Fassung des Habilitationsvortrags vom 10. Juli 1963. Er ist geprägt von der Spiegel-Affäre 1962 und den daran anschlieBenden Protesten (vgl. Bering 2010, S. 354 ff.). Die Bedeutung der Spiegel-Affäre, so Lepsius (1964, S. 89 f./242, s. Tab. 1), liege in der Koalition unterschiedlicher Kritikformen, die, kurzfristig zu einem Bündnis zusammengekommen, zu einem Konsens über gewisse Wertestandards (der Presse- und Meinungsfreiheit in diesem Fall) beigetragen und den Versuch der Regierung, ein Interpretationsmonopol zu schaffen, vereitelt hätten. 
Intellektuelle werden nicht, wie Lepsius (1964, S. 79 ff./234, s. Tab. 1) kritisch gegenüber der Intellektuellensoziologie Mannheims und Geigers schreibt, zusammengehalten durch ein freischwebend geistiges Band oder bilden nur ein „Häuflein Einzelpersonen“, die individuell allein nach ihrem Gewissen handeln; Intellektuelle rekrutieren sich ihm zufolge vielmehr aus der Reihe der „Intelligenzberufe“; man werde nicht allein aus einer persönlichen Haltung Intellektueller, dann bedürfte es eher einer Psychologie der Intellektuellen als einer Intellektuellensoziologie (Lepsius 1964, S. 81/235, s. Tab. 1), sondern aus einer bestimmten sozialen Situation heraus. ${ }^{28}$ In Anlehnung an Joseph A. Schumpeter werden für ihn „Intelligenzler“ zu Intellektuellen ,immer dann und nur solange sie Kritik üben“ (Lepsius 1964, S. 82/235, s. Tab. 1). ${ }^{29}$ Er unterscheidet drei Formen von Kritik, die im Rahmen der Spiegel-Affäre zusammengefunden hätten: 1. die kompetente Kritik, ein Fachurteil zum Beispiel (,Kritik von einem Angehörigen der Profession im Rahmen der Profession“, Lepsius 1964, S. 83/237), 2. Die quasi-kompetente Kritik (etwa gut informierte Journalisten) und 3. die inkompetente (intellektuelle) Kritik. Letztere kann sowohl legitim als auch illegitim sein. Legitim ist sie, sofern sie sich ,,auf Werte bezieht, über deren Gültigkeit als Leitbilder sozialen Verhaltens Konsensus besteht. Illegitim hingegen ist jene Kritik, deren Urteilsbasis von Werten oder Wertkombinationen gebildet wird, über die kein Konsensus besteht und deren Gültigkeit bestritten wird“ (Lepsius 1964, S. 87/240, s. Tab. 1).

Die Wirkmächtigkeit der inkompetenten, intellektuellen Kritik hängt nach Lepsius von dem Grad der Legitimität ab; werde die Kritik als illegitim definiert, so avanciere der Intellektuelle zum Verfolgten oder zum Revolutionär. Legitimität definiere sich demgemäß über den Konsens über bestimmte Werte in einer Gesellschaft sowie durch den Grad, ,,in dem Grundwerte überhaupt allgemein interpretiert werden dürfen“ (Lepsius 1964, S. 87/240, s. Tab. 1). Das verweist wiederum auf die Art und Weise von „Öffentlichkeit“ (vgl. Habermas 1962), mit deren Strukturwandel, so könnte man Lepsius mit Habermas (2006) weiterdenken, sich allerdings auch die Sozialfigur des Intellektuellen ändert.

Das Engagement der Intellektuellen konnte in der Öffentlichkeit der 1960er und 1970er-Jahre nur deshalb eine gewisse Resonanz hervorrufen, weil ihre Interventio-

\footnotetext{
${ }^{28}$ Wolfgang Eßbach (1988, S. 17) hat diese Perspektive, die mit ihrem Blick auf soziale Situation, Interaktions- und davon ausgehenden Situationsdefinitionen und Interpretationsprozessen des Sozialen durch die Intellektuellen in gewisser Weise auf eine pragmatistische Sichtweise auf das soziale Phänomen der Intellektuellen verweist, in seiner Studie der Junghegelianer folgendermaßen auf den Punkt gebracht: Intellektuelle „bilden die gesellschaftlichen Interessen nicht einfach ab, wie dies Ideologiekritik und Wissenssoziologie im Kern nahelegen, sondern sie bilden eine soziale Situation, in der die gesellschaftlichen Widersprüche, die divergierenden sozialen Interessen in einer anderen Weise erscheinen und erscheinen müssen, weil die Versammlung der Intelligenz selbst eine soziale Tatsache ist.“.

29 Innerhalb der Intellektuellenforschung hat sich nach langjährigen Kontroversen folgende Definition herausgebildet (vgl. Peter 2001b, S. 240; folgende Definition übernehme ich aus Moebius 2010a, S. 42): Als Intellektuelle sind Menschen zu bezeichnen, die wissenschaftlich, künstlerisch, religiös, literarisch oder journalistisch tätig sind, dort Kompetenzen erworben haben und qualitativ ausgewiesen sind und in die öffentlichen Auseinandersetzungen und Diskurse kritisch oder affirmativ intervenieren und Position beziehen; sie sind dabei nicht notwendig an einen bestimmten politischen, ideologischen oder moralischen Standort gebunden; folglich kann es sie in unterschiedlichen politischen Lagern oder Strömungen sowie innerhalb und außerhalb institutioneller Bindungen geben.
} 
nen und ihre Rolle als „Störfaktor“ (Schumpeter) auf Anerkennung und Reputation ihrer journalistischen, künstlerischen oder wissenschaftlichen Kompetenz beruhten. Den klassischen Intellektuellen, wie etwa Jean-Paul Sartre oder Theodor W. Adorno, war ein gesellschaftlicher Stellvertretungsanspruch sowie eine radikale Kritik von Herrschaft gemeinsam. Ganz anders der neue Typus des Intellektuellen, der seit einigen Jahren auf die Bühne und ins Rampenlicht medialer Aufmerksamkeit tritt: Der Medienintellektuelle. Wesentliche Merkmale der klassischen Intellektuellen treffen auf die Medienintellektuellen nicht mehr zu. Für sie ist der Maßstab in erster Linie Prominenz, die sie durch ihre Auftritte und Medienpräsenz erworben haben (vgl. Moebius 2010b).

Unterliegen Soziologinnen und Soziologen, sofern sie als Intellektuelle auftreten, dann nicht auch den gegenwärtigen Gefahren des gesellschaftlichen Strukturwandels der Öffentlichkeit und des damit verbundenen Wandels der Sozialfigur des Intellektuellen, zu bloßen aufmerksamkeitserheischenden Medienintellektuellen zu mutieren (vgl. Habermas 2006; Moebius 2010a, 2010b)? Oder gelingt es ihnen als Intellektuelle, diesen Versuchungen zu widerstehen und ihre eigene Position soziologisch zu reflektieren (vgl. Bourdieu 2002) und die, gemäß Lepsius (1964, S. 90/242, s. Tab. 1), ,wesentliche Funktion von Kritik“ zu erfüllen, nämlich ,immer aufs Neue einen materiellen Konsensus in der Gesellschaft über die Gültigkeit bestimmter Wertstandards herbeizuführen und die Deutungsmöglichkeiten offenzuhalten“"?

Ob Soziologinnen und Soziologen, ja die Soziologie überhaupt ein „Werkzeug der Kritik und der Opposition“ sein soll, wie dies unter anderem einmal der frühere Herausgeber der KZfSS René König (1965, S. 26) in ,Soziologie als Oppositionswissenschaft und als Gesellschaftskritik“ eingefordert hat, ist allerdings ein Streitpunkt, der fast so alt wie die Soziologie selbst ist und spätestens seit dem Werturteilsstreit (vgl. Albert 2010) zu einem Dauerthema im soziologischen Diskurs avancierte, das sich bis hin zu aktuellen Diskussionen um „symbolische Gewalt“ (Moebius und Wetterer 2011) und ,public sociology“ erstreckt (vgl. Burawoy et al. 2015).

Was aber, wenn diese Debatten, ob Soziologinnen und Soziologen intellektuell tätig werden sollen oder nicht, zunehmend obsolet erscheinen, weil diese im Rahmen der Aufmerksamkeitsökonomie der Medien immer weniger Gehör finden und im Gegensatz etwa zu Politikwissenschaftlern oder Ökonomen nicht mehr als Experten zu einem diskursiven Austausch (sofern es überhaupt noch um einen solchen geht und nicht um „Confrontainment“) eingeladen werden? Fehlt es bei den Soziologinnen und Soziologen an Medienintellektuellen, die perfekt auf der Klaviatur des medialen Feldes spielen können? Möchten sie überhaupt als intellektuelle Kritiker zu Themen, die ihren Forschungsgegenstand, die Gesellschaft, betreffen Stellung nehmen? Oder verweigern sie sich gar, den Wandel des Intellektuellen zum Performancekünstler mitzumachen, der für die Teilnahme an diesem „Spiel“ notwendig erscheint? Denn das Spiel verlangt nicht die Beherrschung wissenschaftlicher Grundregeln und fachinterner Standards, sondern neben gezielter Selbstinszenierung und Anhäufung medialen Kapitals insbesondere Vereinfachungen, ideologische Schnellschüsse oder unausgegorene Einwürfe, man denke etwa an Peter Sloterdijks (2009) Propagierung einer „Revolution der gebenden Hand“, der zufolge soziale Ungleichheiten durch freiwillige Almosen der Reichen aufgehoben werden sollten. Da scheint eine Verweigerungshaltung seitens der soziologischen Intellektuellen einerseits logisch, 
andererseits könnte diese Situation jedoch auch umgekehrt in eine Haltung münden, offensiv zur gesellschaftlichen Umgestaltung und zur Wiederbelebung einer kritischen, öffentlichen Vernunft beitragen zu wollen (vgl. Bourdieu 1998, S. 17).

Die Logik und die Kriterien des medialen Feldes, das heißt der Drang nach Dramatisierung, Theatralisierung, Ästhetisierung, Storytelling, Erlebnisorientierung, Personalisierbarkeit und Unterhaltung (vgl. Bourdieu 1998; Dörner 2001; Meyer 2001, „Mediokratie“), der postmoderne Strukturwandel der Öffentlichkeit, bei dem sich die Teilnahmebedingungen, die Orte und die Formen von Öffentlichkeit radikal gewandelt haben (vgl. Münker 2009) und der damit einhergehende Wandel der Anforderungen, als Intellektuelle überhaupt noch Gehör zu finden, das alles sind mögliche Elemente, die eine Abwesenheit von Soziologinnen und Soziologen in öffentlichen Diskussionen erklärbar machen.

Sie hätten in den öffentlichen Debatten zu aktuellen Themen, wie den Migrationsprozessen, dem Rechtpopulismus oder ökonomischen Krisen, durchaus etwas zu sagen. Es ist ja nicht so, dass die soziologische Profession nicht zu diesen Themen geforscht hätte. Und dennoch hat es den Anschein, dass sie nur als ,inkompetente intellektuelle Kritiker" (Lepsius) wahrgenommen und eher Vertreterinnen und Vertreter der Politik- oder Wirtschaftswissenschaften zu gegenwärtigen Problemlagen befragt werden. Eine weitere Erklärung dessen könnte sein, dass die Soziologinnen und Soziologen zwar noch als Experten auf dem Gebiet allgemeiner gesellschaftlicher Fragen, Systemkomplexität und sozialer Probleme betrachtet werden; auch ihre Zeitdiagnosen werden gerne von einem breiteren Publikum gelesen, weisen sie ja zentrale Elemente der medialen Logik wie etwa Dramatisierung oder Storytelling auf (vgl. Volkmann 2015, S. 148 f.); die allgemeine Perspektive auf Gesellschaft wird auch in diesen Zeitdiagnosen sichtbar, denn in den meisten Fällen erstrecken sie sich über den Ausschnitt einzelner gesellschaftlicher Teilbereiche hinaus analytisch auf „die Gesellschaft als Ganzes“ (vgl. Schimank 2000, S. 14). Während Soziologinnen und Soziologen also zwar noch als Expertinnen und Experten allgemeiner gesellschaftlicher Prozesse wie Beschleunigung, Resonanz, Angst, Erlebnisorientierung etc. geschätzt, gelesen und in den Feuilletons diskutiert werden, hat sich dagegen das Bewusstsein und die Wahrnehmung der gesellschaftlichen Ausdifferenzierung und teilsystemischen Komplexität schon so weit verbreitet und vertieft, dass die Öffentlichkeit Probleme nicht mehr als gesellschaftlich vermittelte verstehen kann. Für die Deutung spezifischer Fragestellungen wird statt auf Interpretationen des Ganzen weitaus eher auf Experten für Detailfragen von Teilsystemen zurückgegriffen. Diese treten dann meist nur noch als Fachvertreter auf, nicht mehr als Intellektuelle, auch nicht mehr als ,spezifische Intellektuelle“ im Sinne Michel Foucaults (1978, S. 46 ff.). „Spezifische Intellektuelle“ sind nach Foucaults Verständnis zwar auch Experten auf ihrem Fachgebiet, greifen aber in dieser Rolle in gesellschaftliche Debatten und Missstände ein, legen deren Bedingungen offen und vertreten universelle Werte. Dadurch hören sie auf, bloße Experten zu sein. Wenn also in den Medien oder anderen Orten der Öffentlichkeit heute Expertise gefragt ist, dann wird, so meine These, im Allgemeinen sowohl auf eine gesellschaftstheoretische Perspektive als auch auf intellektuelle Kritik zugunsten von Expertinnen und Experten mit „kompetenter Kritik“ im Sinne Lepsius verzichtet. Darunter verstand er spezialisierte Akteure, die sich sowohl angeblich wertneutral auf die Deskription betreffender 
Felder (Politik, Wirtschaft) beschränken als auch es vermeiden, universelle Werte oder komplexe gesellschaftliche Kontexte kritisch zur Sprache zu bringen. Wie bei soziologischen Zeitdiagnosen sollte deshalb auch hier die eingangs gestellte, soziologiehistorisch relevante Frage lauten: Von welchen Deutungs-, Wahrnehmungs- und Ordnungsmustern lassen sich nicht nur die professionellen Beobachter der Gesellschaft, die Soziologinnen und Soziologen, sondern auch die Expertinnen und Experten anderer Fächer leiten? Soziologiehistorisch geschärfte Kritik reflektiert also: Was beeinflusste, förderte oder behinderte in der scientific community das Verständnis gesellschaftlicher Prozesse und Probleme? Welche „Gesellschaft“ konstruieren die Expertinnen und Experten, welche „Gesellschaft“ schreiben sie als alternativlos fest?

Und schließlich hat sicherlich der tief im Disziplinbewusstsein verankerte Werturteilsstreit damit zu tun, dass Soziologinnen und Soziologen zuweilen gut begründete, zuweilen aber auch unbegründete Hemmungen haben, in der Öffentlichkeit zu intervenieren, ihre Expertise einzubringen und ihre fachlich basierte intellektuelle Kritik vorzutragen. Intellektuelle Kritik üben, heißt keineswegs wissenschaftliche Standards aufzugeben, im Gegenteil, denn das Problem besteht ,gar nicht in einem vermeintlich unüberbrückbaren Widerspruch von Wertorientierung und Objektivität. Soziologen und Soziologinnen stehen ihrem Forschungsgegenstand ja nicht wie einem fernen Planeten gegenüber, sondern sie sind selbst ein Teil dessen, was sie erforschen. Sie sind eingebunden in die widersprüchlichen gesellschaftlichen Interessen und Handlungsziele. Diese Tatsache müssen sie kritisch reflektieren, statt sie voluntaristisch abspalten und verleugnen zu wollen. Da es kein interessenloses, wertfreies Forschen gibt, ist wissenschaftliche Wertfreiheit eine Fiktion. Entscheidend ist vielmehr, dass die forschenden Soziologen erstens die eigene normative Orientierung offen legen und nicht opportunistisch verschleiern, zweitens die Standards wissenschaftlicher Professionalität achten und drittens anerkennen, dass ihr normativer Standpunkt einerseits und die Ergebnisse ihres Forschungsprozesses andererseits in Widerspruch zueinander treten können. Mit anderen Worten: Parteilichkeit in der Soziologie erweist sich nur dann als unwissenschaftlich, wenn sie die Ergebnisse der zu erforschenden Gegenstände zu Gunsten dieser Parteilichkeit manipuliert oder die Offenheit der Ergebnisse ausschließt“" (Peter 2016, S. 306).

Nicht zuletzt Pierre Bourdieu (1991, S. 18 ff.; vgl. auch Burawoy 2015, S. 33 ff.) hat vehement darauf aufmerksam gemacht, dass soziologische Kritik jedoch ein hohes Maß an Selbstreflexion einschließen muss. Das erinnert an Mannheims Hinweis auf die Standortverbundheit allen Denkens und wird auch jüngst von Armin Nassehi (2015) im Rahmen seines Konzepts der vernetzten Intelligenz und der Übersetzungskonflikte als wirksamkeitsförderndes Element von Kritik hervorgehoben. Kritik habe also stets die „unhintergehbare Perspektivität der eigenen Perspektive“ zu berücksichtigen (Nassehi 2015, S. 283). Durch diese Selbstreflexion muss öffentliche und intellektuelle Kritik keineswegs gelähmt werden, sondern kann im Gegenteil das Engagement für die eigenen Möglichkeiten intellektueller Intervention, aber auch den Kampf für die Autonomie wissenschaftlicher Produktion und Distribution verbessern.

Trotz der aktuellen medialen Marginalisierung soziologischer Gesellschaftskritik lassen sich jedoch seit einiger Zeit Tendenzen eines sogenannten public turn 
in der Soziologie beobachten, zu dem Michael Burawoys Konzept der public sociology maßgeblich beigetragen hat (vgl. Aulenbacher und Dörre 2015, S. 12). Den wirklichen ,Tigersprung“ in die Öffentlichkeit schafft die Soziologie ausgehend von Burawoys Konzept nur dann, wenn es nicht darauf ankommt, möglichst oft und medienwirksam in der Öffentlichkeit aufzutreten, sondern wenn sie inhaltlich etwas zu sagen hat (vgl. Aulenbacher und Dörre 2015, S. 12), was auf die gesellschaftlichen Probleme und Prozesse unserer Zeit unmittelbar antwortet und Lösungswege aufzeigt (so wie es zum Beispiel in der intellektuellen Kritik anlässlich der von Lepsius erwähnten Spiegel-Affäre sichtbar wurde). Burawoy (2015, S. 41) selbst verknüpft diese öffentliche Wirksamkeit und Kritik mit der Rolle, die die Soziologie für die Zivilgesellschaft einnimmt. Ökonomen und Politikwissenschaftler neigen aus seiner Sicht dazu, entweder der bestehenden politischen Ordnung oder der Ökonomie des Marktes das Wort zu reden, was sie für die mediale Öffentlichkeit ungefährlich erscheinen lässt. Die von ihm vertretene public sociology hingegen sei nicht einfach öffentliches und diskursives Räsonnement über Gesellschaft, sie vertrete vielmehr eine dezidiert kapitalismuskritische, globale Perspektive vom Standpunkt der Zivilgesellschaft: „Die Bedeutung der öffentlichen Soziologie besteht also darin, Bündnisse zu schmieden mit Organisationen, Institutionen, Gemeinschaften und Bewegungen, die ebenfalls mit der Offensive eines Zusammenschlusses von Staat und Markt konfrontiert sind. [...] Aber unser Engagement muss maßvoll und bedächtig sein, ohne die für eine ernsthafte professionelle Soziologie nötige Autonomie aufzuopfern, und dafür brauchen wir eine aktive kritische Soziologie“ (Burawoy 2015, S. 41). Inwieweit Burawoys Plädoyer innerhalb der soziologischen scientific community auf Zustimmung stoßen wird und ob sich public sociology auch öffentlich Gehör verschaffen kann, bleibt angesichts der aktuellen gesellschaftlichen Prozesse und des Strukturwandels der Wissenschaft und der Öffentlichkeit eine offene Frage, deren Beantwortung nicht zuletzt von den Soziologinnen und Soziologen selbst abhängt.

Open access funding provided by University of Graz.

Open Access Dieser Artikel wird unter der Creative Commons Namensnennung 4.0 International Lizenz (http://creativecommons.org/licenses/by/4.0/deed.de) veröffentlicht, welche die Nutzung, Vervielfältigung, Bearbeitung, Verbreitung und Wiedergabe in jeglichem Medium und Format erlaubt, sofern Sie den/die ursprünglichen Autor(en) und die Quelle ordnungsgemäß nennen, einen Link zur Creative Commons Lizenz beifügen und angeben, ob Änderungen vorgenommen wurden. 


\section{Anhang}

Tab. 1 Aufsätze im Sonderheft

\begin{tabular}{|c|c|c|c|}
\hline 1921 & $\mathrm{H} 1$ & Wiese, Leopold von & $\begin{array}{l}\text { Zur Einführung: Die gegenwärtigen Aufgaben } \\
\text { einer deutschen Zeitschrift für Soziologie }\end{array}$ \\
\hline 1928 & $\mathrm{H} 2$ & Mannheim, Karl & Das Problem der Generation \\
\hline 1928 & $\mathrm{H} 3$ & Mannheim, Karl & Das Problem der Generation (Schluss) \\
\hline 1934 & $\mathrm{H} 2$ & Geiger, Theodor & $\begin{array}{l}\text { Natürliche Auslese, soziale Schichtung und das } \\
\text { Problem der Generationen }\end{array}$ \\
\hline 1951 & $\mathrm{H} 2$ & Schelsky, Helmut & Die Flüchtlingsfamilie \\
\hline 1958 & $\mathrm{H} 2$ & Dahrendorf, Ralf & $\begin{array}{l}\text { Homo Sociologicus. Ein Versuch zur Geschichte, } \\
\text { Bedeutung und Kritik der Kategorie der Sozialen } \\
\text { Rolle. Josef König zum 65. Geburtstag (Teil I) }\end{array}$ \\
\hline 1958 & $\mathrm{H} 3$ & Dahrendorf, Ralf & $\begin{array}{l}\text { Homo Sociologicus. Ein Versuch zur Geschichte, } \\
\text { Bedeutung und Kritik der Kategorie der Sozialen } \\
\text { Rolle (Teil II) }\end{array}$ \\
\hline 1962 & $\mathrm{H} 2$ & Popper, Karl R & Die Logik der Sozialwissenschaften \\
\hline 1964 & $\mathrm{H} 1$ & Lepsius, Rainer M & Kritik als Beruf. Zur Soziologie der Intellektuellen \\
\hline 1965 & $\mathrm{H} 1$ & Scheuch, Erwin K & $\begin{array}{l}\text { Sozialer Wandel und Sozialforschung. Über die } \\
\text { Beziehungen zwischen Gesellschaft und empiri- } \\
\text { scher Sozialforschung }\end{array}$ \\
\hline 1965 & H3 & Adorno, Theodor W & Notiz über sozialwissenschaftliche Objektivität \\
\hline 1968 & $\mathrm{H} 3$ & $\begin{array}{l}\text { Kleining, Gerhard; } \\
\text { Moore, Harriett }\end{array}$ & $\begin{array}{l}\text { Soziale Selbsteinstufung (SSE). Ein Instrument zur } \\
\text { Messung sozialer Schichten }\end{array}$ \\
\hline 1971 & $\mathrm{H} 3$ & $\begin{array}{l}\text { Beck, Ulrich; Gerns- } \\
\text { heim, Elisabeth }\end{array}$ & $\begin{array}{l}\mathrm{Zu} \text { einer Theorie der Studentenunruhen in fortge- } \\
\text { schrittenen Industriegesellschaften }\end{array}$ \\
\hline 1975 & $\mathrm{H} 4$ & Tenbruck, Friedrich $\mathrm{H}$ & Das Werk Max Webers \\
\hline 1978 & $\mathrm{H} 2$ & Luhmann, Niklas & Handlungstheorie und Systemtheorie \\
\hline 1979 & $\mathrm{H} 4$ & Neidhardt, Friedhelm & $\begin{array}{l}\text { Das innere System sozialer Gruppen. Ansätze zur } \\
\text { Gruppensoziologie }\end{array}$ \\
\hline 1984 & $\mathrm{H} 4$ & Esser, Hartmut & $\begin{array}{l}\text { Figurationssoziologie und Methodologischer Indi- } \\
\text { vidualismus. Zur Methodologie des Ansatzes von } \\
\text { Norbert Elias }\end{array}$ \\
\hline 1985 & $\mathrm{H} 1$ & Kohli, Martin & $\begin{array}{l}\text { Die Institutionalisierung des Lebenslaufs. Histori- } \\
\text { sche Befunde und theoretische Argumente }\end{array}$ \\
\hline 1987 & H3 & Streeck, Wolfgang & $\begin{array}{l}\text { Vielfalt und Interdependenz. Überlegungen zur } \\
\text { Rolle von intermediären Organisationen in sich } \\
\text { ändernden Umwelten }\end{array}$ \\
\hline 1988 & $\mathrm{H} 4$ & Schimank, Uwe & Gesellschaftliche Teilsysteme als Akteurfiktionen \\
\hline 1991 & $\mathrm{H} 2$ & Opp, Karl-Dieter & $\begin{array}{l}\text { DDR ' } 89 . \text { Zu den Ursachen einer spontanen Revo- } \\
\text { lution }\end{array}$ \\
\hline 1992 & $\mathrm{H} 2$ & $\begin{array}{l}\text { Diekmann, Andreas; } \\
\text { Preisendörfer, Peter }\end{array}$ & $\begin{array}{l}\text { Persönliches Umweltverhalten. Diskrepanzen } \\
\text { zwischen Anspruch und Wirklichkeit }\end{array}$ \\
\hline 1994 & H1 & $\begin{array}{l}\text { Alba, Richard D.; } \\
\text { Handl, Johann; } \\
\text { Müller, Walter }\end{array}$ & $\begin{array}{l}\text { Ethnische Ungleichheit im deutschen Bildungssys- } \\
\text { tem }\end{array}$ \\
\hline 1997 & H3 & $\begin{array}{l}\text { Blossfeld, Hans-Peter; } \\
\text { Timm, Andreas }\end{array}$ & $\begin{array}{l}\text { Der Einfluß des Bildungssystems auf den Hei- } \\
\text { ratsmarkt. Eine Längsschnittanalyse der Wahl des } \\
\text { ersten Ehepartners im Lebenslauf }\end{array}$ \\
\hline 2016 & $\begin{array}{l}\text { (Für das } \\
\text { Sonderheft } \\
\text { erstellt) }\end{array}$ & $\begin{array}{l}\text { Rauhut, Heiko; } \\
\text { Winter, Fabian }\end{array}$ & $\begin{array}{l}\text { Vernetzung und Positionierung der Kölner Zeit- } \\
\text { schrift für Soziologie (KZfSS) in der länder-, diszi- } \\
\text { plinen- und spachübergreifenden Diskussion }\end{array}$ \\
\hline
\end{tabular}




\section{Literatur}

Abels, Heinz. 2010. Die Geschichte einer aufregenden Jugendsünde und die lange Wirkung einer Fußnote. Nachwort. In Homo sociologicus. Ein Versuch zur Geschichte, Bedeutung und Kritik der Kategorie der sozialen Rolle, Hrsg. Ralf Dahrendorf, 115-162. Wiesbaden: VSVerlag für Sozialwissenschaften.

Albert, Gert. 2010. Der Werturteilsstreit. In Soziologische Kontroversen. Eine andere Geschichte der Wissenschaft vom Sozialen, Hrsg. Georg Kneer und Stephan Moebius, 14-45. Berlin: Suhrkamp.

Albrecht, Clemens. 2013. Nachwort. In Emile Durkheim. Zur Bestimmung der französischen Soziologie in Deutschland. Schriften Bd. 8, René König, 387-413. Wiesbaden: Springer VS.

Alemann, Heine von. 1981. Leopold von Wiese und das Forschungsinstitut für Sozialwissenschaften in Köln 1919 bis 1934. In Geschichte der Soziologie, Bd. 2, Hrsg. Wolf Lepenies, 349-389. Frankfurt a. M.: Suhrkamp.

Alexander, Jeffrey C. 1988. The new theoretical movement. In Handbook of Sociology, Hrsg. Neil J. Smelser, 77-101. Newbury Park: Sage.

Aulenbacher, Brigitte, und Klaus Dörre. Michael Burawoys Soziologie - eine kapitalismus- und wissenschaftskritische Herausforderung. In Public Sociology. Öffentliche Soziologie gegen Marktfundamentalismus und globale Ungleichheit, Hrsg. Brigitte Aulenbacher, Klaus Dörre und Michael Burawoy. 9-22. Weinheim: Juventa.

Babka von Gostomski, Christian, Beate Küpper und Wilhelm Heitmeyer. 2007. Fremdenfeindlichkeit in den Bundesländern. Die schwierige Lage in Ostdeutschland. In Deutsche Zustände. Folge 5, Hrsg. Wilhelm Heitmeyer, 102-128. Frankfurt a. M.: Suhrkamp.

Bach, Maurizio. Hrsg. 2000. Die Europäisierung nationaler Gesellschaften. Kölner Zeitschrift für Soziologie und Sozialpsychologie, Sonderheft 40. Wiesbaden: Westdeutscher Verlag.

Barboza, Amalia, und Klaus Lichtblau. 2009. Einleitung. In Schriften zur Wirtschafts- und Kultursoziologie. Karl Mannheim, 7-29. Wiesbaden: VS Verlag für Sozialwissenschaften.

Beckert, Jens, und Christoph Deutschmann. Hrsg. 2009. Wirtschaftssoziologie. Kölner Zeitschrift für Soziologie und Sozialpsychologie, Sonderheft 49. Wiesbaden: VS Verlag für Sozialwissenschaften.

Bering, Dietz. 2010. Die Epoche der Intellektuellen. 1898-2001. Geburt. Begriff. Grabmal. Berlin: Berlin University Press.

Blomert, Reinhard. 1999. Intellektuelle im Aufbruch. Karl Mannheim, Alfred Weber, Norbert Elias und die Heidelberger Sozialwissenschaften in der Zwischenkriegszeit. München: Hanser.

Bohle, Hans Hartwig. 1997. Armut trotz Wohlstand. In Was treibt die Gesellschaft auseinander? Bundesrepublik Deutschland: Auf dem Weg von der Konsens- zur Konfliktgesellschaft, Bd. 1, Hrsg. Wilhelm Heitmeyer, 118-155. Frankfurt a. M.: Suhrkamp.

Borggräfe, Henning, und Sonja Schnitzler. 2014. Die Deutsche Gesellschaft für Soziologie und der Nationalsozialismus. Verbandsinterne Transformationen nach 1933 und nach 1945. In Soziologie und Nationalsozialismus. Positionen, Debatten, Perspektiven, Hrsg. Michaela Christ und Maja Suderland, 445-479. Berlin: Suhrkamp.

Bourdieu, Pierre. 1991. Die Intellektuellen und die Macht. Hrsg. Irene Dölling. Hamburg : VSA.

Bourdieu, Pierre. 1998. Über das Fernsehen. Frankfurt a. M.: Suhrkamp.

Bourdieu, Pierre. 2002. Ein soziologischer Selbstversuch. Frankfurt a. M.: Suhrkamp.

Bourdieu, Pierre, und Jean-Claude Passeron. 1971. Die Illusion der Chancengleichheit: Untersuchungen zur Soziologie des Bildungswesens am Beispiel Frankreichs. Texte und Dokumente zur Bildungsforschung. 1. Aufl. Stuttgart: Klett.

Bude, Heinz. 2002. Die Charismatiker des Anfangs. Helmuth Plessner, René König, Theodor W. Adorno und Helmut Schelsky als Gründer einer Soziologie in Deutschland. In Lebenszeiten. Erkundungen zur Soziologie der Generationen, Hrsg. Günter Burkart und Jürgen Wolf, 407-419. Opladen: Leske \& Budrich.

Bude, Heinz. 2014. Gesellschaft der Angst. Hamburg: Hamburger Edition.

Bude, Heinz, und Andreas Willisch. 2007. Exklusion. Die Debatte über die „Überflüssigen“. Frankfurt a. M.: Suhrkamp.

Burawoy, Michael. 2015. Soziologie - going public, going global. Einleitung. In Public Sociology. Öffentliche Soziologie gegen Marktfundamentalismus und globale Ungleichheit, Hrsg. Michael Burawoy, Brigitte Aulenbacher und Klaus Dörre, 23-47. Weinheim: Juventa.

Burawoy, Michael, Brigitte Aulenbacher und Klaus Dörre. Hrsg. 2015. Public Sociology. Öffentliche Soziologie gegen Marktfundamentalismus und globale Ungleichheit. Weinheim: Juventa.

Caspari, Volker, und Klaus Lichtblau. 2014. Franz Oppenheimer. Ökonom und Soziologe der ersten Stunde. Frankfurt a. M.: Societäts-Verlag. 
Christ, Michaela, und Maja Suderland. Hrsg. 2014. Soziologie und Nationalsozialismus. Positionen, Debatten, Perspektiven. Berlin: Suhrkamp.

Conze, Eckart. 2009. Die Suche nach Sicherheit. Eine Geschichte der Bundesrepublik Deutschland von 1949 bis in die Gegenwart. München: Siedler.

Dahms, Hans-Joachim. 1994. Positivismusstreit. Die Auseinandersetzungen der Frankfurter Schule mit dem logischen Posititvismus, dem amerikanischen Pragmatismus und dem kritischen Rationalismus. Frankfurt a. M.: Suhrkamp.

Dahms, Hans-Joachim. 2008. Politisierung der Wissenschaft: Die drei Positivismusstreite. In Was bleibt vom Positivismusstreit?, Hrsg. Reinhard Neck, 19-40. Frankfurt a. M.: Peter Lang.

Dahrendorf, Ralf. 1960. Die drei Soziologien. Zu Helmut Schelskys „Ortsbestimmung der deutschen Soziologie“. Kölner Zeitschrift für Soziologie und Sozialpsychologie 12:120-133.

Dayé, Christian, und Stephan Moebius. Hrsg. 2015. Soziologiegeschichte. Wege und Ziele. Berlin: Suhrkamp.

Demirovic, Axel. 1999. Der nonkonformistische Intellektuelle. Die Entwicklung der Kritischen Theorie zur Frankfurter Schule. Frankfurt a. M.: Suhrkamp.

Dörk, Uwe. 2016. Die Deutsche Gesellschaft für Soziologie (DGS) in der Zwischenkriegszeit (1918-1933): Akademische Etablierung unter dem Zeichen elitär-demokratischer Kreisbildung. In Handbuch Geschichte der deutschsprachigen Soziologie, Bd. 1, Hrsg. Stephan Moebius und Andrea Ploder. Wiesbaden: Springer VS (i.E.)

Dörner, Andreas. 2001. Politainment. Politik in der medialen Erlebnisgesellschaft. Frankfurt a. M.: Suhrkamp.

Dreier, Volker. 2016. Geschichte der Kölner Zeitschrift für Soziologie und Sozialpsychologie. In Geschichte der deutschsprachigen Soziologie, Bd. 1, Hrsg. Stephan Moebius und Andrea Ploder. Doi: 10.1007/978-3-658-07998-7_44-1 (Zugegriffen: 01.07.2016).

Dyk, Silke van, und Stephan Lessenich. Hrsg. 2008. Jena und die deutsche Soziologie. Der Soziologentag 1922 und das Soziologentreffen 1934 in der Retrospektive. Frankfurt a. M: Campus

Dyk, Silke van, und Alexandra Schauer. 2015. „...daß die offizielle Soziologie versagt hat“. Zur Soziologie im Nationalsozialismus, der Geschichte ihrer Aufarbeitung und der Rolle der DGS. 2. Aufl., Jahrbuch für Soziologiegeschichte. Wiesbaden: Springer VS.

Endreß, Martin. 2001. Zur Historizität soziologischer Gegenstände und ihren Implikationen für eine wissenssoziologische Konzeptualisierung von Soziologiegeschichte. In Jahrbuch für Soziologiegeschichte 1997/1998, Hrsg. Carsten Klingemann et al., 65-90. Opladen: Leske \& Budrich.

Esser, Hartmut. 2000. Vorwort. In Der Wandel nach der Wende. Gesellschaft, Wirtschaft, Politik in Ostdeutschland, Hrsg. Hartmut Esser, 7-9. Opladen: Westdeutscher Verlag.

Eßbach, Wolfgang. 1988. Die Junghegelianer. Soziologie einer Intellektuellengruppe. München: Fink.

Fischer, Joachim. 2010. Die Rollendebatte - Der Streit um den „Homo sociologicus“. In Soziologische Kontroversen. Eine andere Geschichte der Wissenschaft vom Sozialen, Hrsg. Georg Kneer und Stephan Moebius, 79-101. Berlin: Suhrkamp.

Fleck, Christian. 2007. Transatlantische Bereicherungen. Zur Erfindung der empirischen Sozialforschung. Frankfurt a. M.: Suhrkamp.

Foucault, Michel. 1978. Wahrheit und Macht. In Dispositive der Macht. Michel Foucault. Über Sexualität, Wissen und Wahrheit, Hrsg. Michel Foucault, 21-54. Berlin: Merve.

Friedrichs, Jürgen, Jürgen Mayer und Wolfgang Schluchter. 1997. Einleitung. In Soziologische Theorie und Empirie. Zum 50jährigen Jubiläum des Westdeutschen Verlags, Hrsg. Jürgen Friedrichs, Jürgen Mayer und Wolfgang Schluchter, VII-X. Opladen: Westdeutscher Verlag.

Görtemaker, Manfred. 2009. Die Berliner Republik. Wiedervereinigung und Neuorientierung. Berlin: be.bra.

Gorges, Irmela. 1986. Sozialforschung in der Weimarer Republik 1918-1933. Frankfurt a. M.: Hain Verlag.

Greshoff, Rainer. 2010. Die Theorienvergleichsdebatte in der deutschsprachigen Soziologie. In Soziologische Kontroversen. Eine andere Geschichte der Wissenschaft vom Sozialen, Hrsg. Georg Kneer und Stephan Moebius, 182-216. Berlin: Suhrkamp.

Habermas, Jürgen. 1962. Strukturwandel der Öffentlichkeit. Untersuchungen zu einer Kategorie der bürgerlichen Gesellschaft. Neuwied: Luchterhand.

Habermas, Jürgen. 1981. Theorie des kommunikativen Handelns. 2 Bde. Frankfurt a. M.: Suhrkamp.

Habermas, Jürgen. 2006. Ein avantgardistischer Spürsinn für Relevanzen. Was den Intellektuellen auszeichnet. Blätter für deutsche und internationale Politik 51:551-557.

Haug, Frigga. 1972. Kritik der Rollentheorie und ihrer Anwendung in der bürgerlichen deutschen Soziologie. Frankfurt a. M.: Fischer. 
Haupts, Leo. 2007. Die Universität zu Köln im Übergang vom Nationalsozialismus zur Bundesrepublik. Köln: Böhlau.

Hauser, Richard. 2010. „Nahblick“ und ,Weitblick“. Erste Schritte zur Erforschung des sozialen und politischen Wandels in den neuen Bundesländern und frühe Prognosen. In Leben in Ost- und Westdeutschland. Eine sozialwissenschaftliche Bilanz der deutschen Einheit 1990-2010, Hrsg. Peter Krause und Ilona Ostner, 57-81. Frankfurt a. M.: Campus.

Heitmeyer, Wilhelm. 1997. Einleitung: Auf dem Weg in eine desintegrierte Gesellschaft. In Was treibt die Gesellschaft auseinander? Bundesrepublik Deutschland: Auf dem Weg von der Konsens- zur Konfliktgesellschaft, Bd. 1, Hrsg. Wilhelm Heitmeyer, 9-26. Frankfurt a. M.: Suhrkamp.

Herbert, Ulrich. 2014. Geschichte Deutschlands im 20. Jahrhundert. München: Beck.

Holzhauser, Nicole. 2015. Definitorische und methodologische Probleme bei der Analyse der soziologischen Disziplinentwicklung zur Zeit des Nationalsozialismus. In Österreichische Zeitschrift für Soziologie 40:129-146.

Homann, Harald. 1999. Einleitung. In Friedrich H. Tenbruck. Das Werk Max Webers. Gesammelte Aufsätze zu Max Weber, Hrsg. Harald Homann, VII-XVIV. Tübingen: Mohr-Siebeck.

Honneth, Axel. 1994. Desintegration. Bruchstücke einer soziologischen Zeitdiagnose. Frankfurt a. M.: Fischer.

Joas, Hans. 1978. Die gegenwärtige Lage der soziologischen Rollentheorie. 3. erw. Aufl. Wiesbaden: Akademische Verlagsanstalt.

Joas, Hans, und Martin Kohli. Hrsg. 1993. Der Zusammenbruch der DDR. Soziologische Analysen. Frankfurt a. M.: Suhrkamp.

Joas, Hans, und Wolfgang Knöbl. 2004. Sozialtheorie. Zwanzig einführende Vorlesungen. Frankfurt a. M.: Suhrkamp.

Kaesler, Dirk. 1984. Die frühe deutsche Soziologie und ihre Entstehungsmilieus. Eine wissenschaftssoziologische Untersuchung. Opladen: Westdeutscher Verlag.

Kaesler, Dirk. 1997. Die Gründung des Forschungsinstituts für Soziologie der Universität zu Köln und die zwanziger Jahre. In Soziologie als Berufung. Bausteine einer selbstbewussten Soziologie, Hrsg. Dirk Kaesler, 235-247. Opladen: Westdeutscher Verlag.

Kaesler, Dirk. 2008. Die Soziologie auf der Suche nach akademischer Respektabilität - Eine wissenschaftssoziologische Einordnung der Jenaer Debatten von 1922. In Jena und die deutsche Soziologie. Der Soziologentag 1922 und das Soziologentreffen 1934 in der Retrospektive, Hrsg. Silke van Dyk und Stephan Lessenich, 81-97. Frankfurt a. M.: Campus.

Klingemann, Carsten. 1988. Kölner Soziologie während des Nationalsozialismus. In Nachhilfe zur Erinnerung. 600 Jahre Universität zи Köln, Hrsg. Wolfgang Blaschke, Olaf Hensel, Peter Liebermann und Wolfgang Lindweiler, 76-97. Köln: Pahl-Rugenstein.

Klingemann, Carsten. 1996. Soziologen vor dem Nationalsozialismus: Szenen aus der mißlungenen Selbstgleichschaltung der Deutschen Gesellschaft für Soziologie. In Soziologie im Dritten Reich, Hrsg. Carsten Klingemann, 11-32. Baden-Baden: Nomos.

Klingemann, Carsten. 2009. Soziologie und Politik. Sozialwissenschaftliches Expertenwissen im Dritten Reich und in der frühen westdeutschen Nachkriegssoziologie. Wiesbaden: VS Verlag für Sozialwissenschaften.

Kneer, Georg, und Stephan Moebius. 2010. Vorwort. In Soziologische Kontroversen. Eine andere Geschichte der Wissenschaft vom Sozialen, Hrsg. Georg Kneer und Stephan Moebius, 7-13. Berlin: Suhrkamp.

König, René. 1955. Vorbemerkung des Herausgebers zum Jahrgang VII. Kölner Zeitschrift für Soziologie $1-5$.

König, René. 1961. Zur Soziologie der zwanziger Jahre. In Die Zeit ohne Eigenschaften. Eine Bilanz der zwanziger Jahre, Hrsg. Leonhard Reinisch, 82-118. Stuttgart: Kohlhammer.

König, René. 1965. Soziologie als Oppositionswissenschaft und als Gesellschaftskritik. In Soziologische Orientierungen. Vorträge und Aufsätze, Hrsg. René König, 17-28. Köln: Kiepenheuer \& Witsch.

König, René. 1967. Soziologie. Fischer-Lexikon (Neuausgabe). 1958. Frankfurt a. M.: Fischer.

König, René. 1973. Vorwort. In Handbuch der empirischen Sozialforschung. Bd. 1: Geschichte und Grundprobleme, Hrsg. René König, 3. Aufl., VI-XI. Stuttgart: Enke.

König, René. 1987. Soziologie in Deutschland. Begründer/Verfechter/Verächter. München: Hanser.

König, René. 2002. Freiheit und Selbstentfremdung in soziologischer Sicht. 1961/62. In Arbeit und Beruf in der modernen Gesellschaft, Schriften Bd. 16, Hrsg. Hansjürgen Daheim und Dieter Fröhlich, 7-26. Wiesbaden: VS Verlag für Sozialwissenschaften.

Krause, Peter, und Ilona Ostner. Hrsg. 2010. Leben in Ost- und Westdeutschland. Eine sozialwissenschaftliche Bilanz der deutschen Einheit 1990-2010, Frankfurt a. M.: Campus. 
Leibfried, Stephan, und Wolfgang Voges. 1992. Armut im modernen Wohlfahrtsstaat. Kölner Zeitschrift für Soziologie und Sozialpsychologie, Sonderheft 32. Opladen: Westdeutscher Verlag.

Lepenies, Wolf. 1981. Einleitung. Studien zur kognitiven, sozialen und historischen Identität der Soziologie. In Geschichte der Soziologie. Studien zur kognitiven, sozialen und historischen Identität einer Disziplin, Bd. 1, Hrsg. Wolf Lepenies, I-XXXV. Frankfurt a. M.: Suhrkamp.

Lepsius, M. Rainer. 1979. Die Entwicklung der Soziologie nach dem Zweiten Weltkrieg 1945 bis 1967. In Deutsche Soziologie seit 1945. Kölner Zeitschrift für Soziologie und Sozialpsychologie, Sonderheft 21, Hrsg. Günther Lüschen, 25-70. Opladen: Westdeutscher Verlag.

Lepsius, M. Rainer. 1981. Soziologie in Deutschland und Österreich 1918-1945. Kölner Zeitschrift für Soziologie und Sozialpsychologie, Sonderheft 23, Hrsg. M. Rainer Lepsius. Opladen: Westdeutscher Verlag.

Lepsius, M. Rainer. 1981a. Die Soziologie der Zwischenkriegszeit: Entwicklungstendenzen und Beurteilungskriterien. In Soziologie in Deutschland und Österreich 1918-1945. Kölner Zeitschrift für Soziologie und Sozialpsychologie, Sonderheft 23, Hrsg. M. Rainer Lepsius, 7-23. Opladen: Westdeutscher Verlag.

Lepsius, M. Rainer. 1981b. Die sozialwissenschaftliche Emigration und ihre Folgen. In Soziologie in Deutschland und Österreich 1918-1945. Kölner Zeitschrift für Soziologie und Sozialpsychologie, Sonderheft 23, Hrsg. M. Rainer Lepsius, 461-500. Opladen: Westdeutscher Verlag.

Lepsius, M. Rainer. 2008. Soziologie als Profession. Hrsg. Adalbert Hepp und Martina Löw, Frankfurt a. M.: Campus.

Lessenich, Stephan, und Frank Nullmeier. Hrsg. 2006. Deutschland-eine gespaltene Gesellschaft. Frankfurt a. M.: Campus.

Lichtblau, Klaus. 1996. Kulturkrise und Soziologie um die Jahrhundertwende. Zur Genealogie der Kultursoziologie in Deutschland. Frankfurt a. M.: Suhrkamp.

Luhmann, Niklas. 1984. Soziale Systeme. Grundriß einer allgemeinen Theorie. Frankfurt a. M.: Suhrkamp.

Lüschen, Günther. 1979. Die Entwicklung der deutschen Soziologie in ihrem Fachschrifttum. Perioden, Sachgebiete und Methode seit 1945. In Deutsche Soziologie seit 1945. Kölner Zeitschrift für Soziologie und Sozialpsychologie, Sonderheft 21, Hrsg. Günther Lüschen, 169-192. Opladen: Westdeutscher Verlag.

Mannheim, Karl. 1931. Wissenssoziologie. In Handwörterbuch der Soziologie, Hrsg. Alfred Vierkandt, 659-680. Stuttgart: Enke.

Mansel, Jürgen, und Barbara Kaletta. 2009. Desintegrationsprozesse, Anerkennungsprobleme und Gruppenbezogene Menschenfeindlichkeit. Ein Ost-West-Vergleich. In Deutsche Zustände. Folge 7, Hrsg. Wilhelm Heitmeyer, 73-92. Frankfurt a. M.: Suhrkamp.

Maus, Heinz. 1959. Bericht über die Soziologie in Deutschland 1933-1945. Kölner Zeitschrift für Soziologie und Sozialpsychologie 11:72-99.

Meja, Volker, und Nico Stehr. Hrsg. 1982. Der Streit um die Wissenssoziologie. Zweiter Band: Rezeption und Kritik der Wissenssoziologie. Frankfurt a. M.: Suhrkamp.

Meyer, Thomas. 2001. Die Soziologie Theodor Geigers. Emanzipation von der Ideologie. Wiesbaden: Westdeutscher Verlag.

Meyer, Thomas. 2001. Mediokratie. Die Kolonisierung der Politik durch die Medien. Frankfurt a. M.: Suhrkamp.

Moebius, Stephan. 2004. Praxis der Soziologiegeschichte. Methodologien, Konzeptionalisierungen und Beispiele soziologiegeschichtlicher Forschung. Hamburg: Kovac.

Moebius, Stephan. 2010a. Intellektuellensoziologie - Skizze zu einer Methodologie. Sozial.Geshcichte Online 2010/2: 37-63. http://duepublico.uni-duisburg-essen.de/servlets/DocumentServlet?id=22136 (Zugegriffen: 6.10.2016).

Moebius, Stephan. 2010b. Der Medienintellektuelle. In Diven, Hacker, Spekulanten. Sozialfiguren der Gegenwart, Hrsg. Stephan Moebius und Markus Schroer, 277-290. Frankfurt a. M.: Suhrkamp.

Moebius, Stephan. 2015. René König und die „Kölner Schule“. Eine soziologiegeschichtliche Annäherung. Wiesbaden: Springer VS.

Moebius, Stephan. 2016a. Methodologie soziologischer Ideengeschichte. In Handbuch Geschichte der deutschsprachigen Soziologie, Bd. 2, Hrsg. Stephan Moebius und Andrea Ploder. Doi: 10.1007/9783-658-07999-4_1-1 (Zugegriffen: 01.07. 2016).

Moebius, Stephan. 2016b. Schulen, Akteure und regionale Zentren in der frühen Geschichte der bundesrepublikanischen Soziologie. In Handbuch Geschichte der deutschsprachigen Soziologie, Bd. 1, Hrsg. Stephan Moebius und Andrea Ploder. Doi: 10.1007/978-3-658-07998-7_14-1 (Zugegriffen: 01. 07. 2016). 
Moebius, Stephan. 2016c. Kontroversen in der deutschsprachigen Soziologie nach 1945. In Handbuch Geschichte der deutschsprachigen Soziologie, Bd. 1, Hrsg. Stephan Moebius und Andrea Ploder. doi:10.1007/978-3-658-07998-7_20-1.

Moebius, Stephan, und Gerhard Schäfer. Hrsg. 2006. Soziologie als Gesellschaftskritik: wider den Verlust einer aktuellen Tradition. Festschrift für Lothar Peter. Hamburg: VSA.

Moebius, Stephan, und Angelika Wetterer. Hrsg. 2011. Symbolische Gewalt. Österreichischen Zeitschrift für Soziologie 36:1-10.

Moebius, Stephan, und Clemens Albrecht. Hrsg. 2014. Kultur-Soziologie. Klassische Texte der neueren deutschen Kultursoziologie. Wiesbaden: Springer VS.

Moebius, Stephan, und Andrea Ploder. Hrsg. 2017. Handbuch der deutschsprachigen Soziologie. 2 Bde. Wiesbaden: Springer VS. (i.E.).

Münker, Stefan. 2009. Emergenz digitaler Öffentlichkeiten. Die Sozialen Medien im Web 2.0. Frankfurt a. M.: Suhrkamp.

Nachtwey, Oliver. 2016. Die Abstiegsgesellschaft. Über das Aufbegehren in der regressiven Moderne. Berlin: Suhrkamp.

Nassehi, Armin. 2015. Die letzte Stunde der Wahrheit. Warum rechts und links keine Alternativen mehr sind und Gesellschaft ganz anders beschrieben werden muss. Hamburg: Murmann.

Neidhardt, Friedhelm. 1982a. Soziale Bedingungen terroristischen Handelns. Das Beispiel der BaaderMeinhof-Gruppe. In Analysen zum Terrorismus. Gruppenprozesse, Bd. 3, Wanda von Baeyer-Katte, Dieter Claessens, Hubert Feger und Friedhelm Neidhardt, 318-392. Opladen: Westdeutscher Verlag.

Neidhardt, Friedhelm, Wanda von Baeyer-Katte, Dieter Claessens und Hubert Fege. 1982b. Analysen zum Terrorismus. Gruppenprozesse, Bd. 3. Opladen: Westdeutscher Verlag.

Neumann, Michael, und Gerhard Schäfer. 1990. „Blick nach vorn...“: Ein Gespräch mit René König. In Jahrbuch für Soziologiegeschichte 1990, Hrsg. Heinz-Jürgen Dahme et al, 219-238. Opladen: Leske \& Budrich.

Nickel, Hildegard. 1995. Frauen im Umbruch der Gesellschaft. Aus Politik und Zeitgeschichte 36-37:23-33.

Nolte, Paul. 2000. Die Ordnung der deutschen Gesellschaft. Selbstentwurf und Selbstbeschreibung im 20. Jahrhundert. München: Beck.

Peter, Lothar. 2001a. Warum und wie betreibt man Soziologiegeschichte. In Jahrbuch für Soziologiegeschichte 1997/98, Carsten Klingemann, Michael Neumann, Karl-Siegbert Rehberg, Ilja Srubar und Erhard Stölting, 9-64. Opladen: Leske \& Budrich.

Peter, Lothar. 2001b. Warum sind die französischen Intellektuellen politisch, die deutschen aber nicht? In Flexibler Kapitalismus. Analyse, Politik und politische Praxis, Hrsg. Hans-Jürgen Bieling, Klaus Dörre, Jochen Steinhilber und Hans-Jürgen Urban, 240-251. Hamburg: VSA.

Peter, Lothar. 2013. Dialektik der Gesellschaft versus „Conscience Collective“? Zur Kritik Theodor W. Adornos an Émile Durkheim. In Émile Durkheim, Hrsg. Tanja Bogusz und Heike Delitz, 73-94. Frankfurt a. M.: Campus.

Peter, Lothar. 2016. Umstrittene Moderne. Soziologische Diskurse und Gesellschaftskritik. Wiesbaden: Springer VS.

Pinn, Irmgard. 1987. Die rassistischen Konsequenzen einer völkischen Anthropologie. In Rassenmythos und Sozialwissenschaften in Deutschland, Hrsg. Carsten Klingemann, 212-241. Opladen: Westdeutscher Verlag.

Pinn, Irmgard, und Michael Nebelung. 1990. Kontinuität durch Verdrängung. In Jahrbuch für Soziologiegeschichte 1990, Hrsg. Heinz-Jürgen Dahme, Carsten Klingemann, Michael Neumann, Karl-Siegbert Rehberg und Ilja Srubar,177-218. Opladen: Leske \& Budrich.

Plessner, Helmuth. 2002. Grenzen der Gemeinschaft. Eine Kritik des sozialen Radikalismus. 1924. Frankfurt a. M.: Suhrkamp.

Plessner, Helmuth. 1974. Soziale Rolle und menschliche Natur. 1960. In Diesseits der Utopie. Ausgewählte Beiträge zur Kultursoziologie, Hrsg. Helmuth Plessner, 23-35. Frankfurt a. M.: Suhrkamp.

Pollack, Detlef. 1990a. Das Ende einer Organisationsgesellschaft. Systemtheoretische Überlegungen zum gesellschaftlichen Umbruch in der DDR. Zeitschrift für Soziologie 19:292-307.

Pollack, Detlef. 1990b. Wer leitete die „Wende“ ein? Überlegungen zum gesellschaftlichen Umbruch in der DDR aus systemtheoretischer Perspektive. Sozialwissenschaften und Berufspraxis 13:167-177.

Rammstedt, Otthein. 1986. Deutsche Soziologie 1933-1945. Die Normalität einer Anpassung. Frankfurt a. M.: Suhrkamp.

Rehberg, Karl-Siegbert. 1979. Form und Prozeß. Zu den katalysatorischen Wirkungschancen einer Soziologie aus dem Exil: Norbert Elias. In Materialien zu Norbert Elias' Zivilisationstheorie, Hrsg. Peter Gleichmann, Johan Gouldsblom und Hermann Korte, 101-169. Frankfurt a. M.: Suhrkamp. 
Rehberg, Karl-Siegbert. 2000. „Großexperiment“ und Erfahrungsschock. Zu einer Forschungsinitiative über das Zusammenwachsen der Deutschen. In Der Wandel nach der Wende. Gesellschaft, Wirtschaft, Politik in Ostdeutschland, Hrsg. Hartmut Esser, 11-27. Opladen: Westdeutscher Verlag.

Ringer, Fritz K. 1987. Die Gelehrten. Der Niedergang der deutschen Mandarine 1880-1933. München: dtv.

Ritsert, Jürgen. 2010. Der Positivismusstreit. In Soziologische Kontroversen. Eine andere Geschichte der Wissenschaft vom Sozialen, Hrsg. Georg Kneer und Stephan Moebius, 102-130. Berlin: Suhrkamp.

Schad, Susanne Petra. 1972. Empirical social research in Weimar-Germany. Paris: Mouton.

Schäfer, Gerhard. 1990. Wider die Inszenierung des Vergessens. Hans Freyer und die Soziologie in Leipzig 1925-1945. In Jahrbuch für Soziologiegeschichte 1990, Hrsg. Heinz-Jürgen Dahme, Carsten Klingemann, Michael Neumann, Karl-Siegbert Rehberg und Ilja Srubar, 121-175. Opladen: Leske \& Budrich.

Schäfer, Gerhard. 1996. Soziologie auf dem Vulkan - Zur Stellung René Königs in der Dreieckskonstellation der westdeutschen Nachkriegssoziologie. In Antifaschismus, Hrsg. Frank Deppe, Georg Fülberth und Rainer Rilling, 370-387. Heilbronn: Distel.

Schäfer, Gerhard. 2000. Die nivellierte Mittelstandsgesellschaft - Strategien der Soziologie in den 50erJahren. In Die janusköpfigen 50er-Jahre. Kulturelle Moderne und bildungsbürgerliche Semantik III., Hrsg. Georg Bollenbeck und Gerhard Kaiser, 115-142. Wiesbaden: VS Verlag für Sozialwissenschaften.

Schäfer, Gerhard. 2014. Der Nationalsozialismus und die soziologischen Akteure der Nachkriegszeit: am Beispiel Helmut Schelskys und Ralf Dahrendorfs. In Soziologie und Nationalsozialismus. Positionen, Debatten, Perspektiven, Hrsg. Michaela Christ und Maja Suderland, 119-161. Berlin: Suhrkamp.

Schäfer, Gerhard. 2015a. Soziologie ohne Marx. Helmut Schelsky als „Starsoziologe“ und Intellektueller im Hamburg der 1950er-Jahre. Supplement der Zeitschrift Sozialismus 1/2015. Hamburg: VSA.

Schäfer, Gerhard. 2015b. Zur Herausbildung des philosophisch-soziologischen Denkens bei Helmut Schelsky in der Ära des Nationalsozialismus. In Helmut Schelsky. Ein deutscher Soziologe im zeitgeschichtlichen, institutionellen und interdisziplinären Kontext, Beiheft 22 der Zeitschrift Rechtstheorie, Hrsg. Reinhard Feldmann et al., 1-40. Berlin: Duncker \& Humblot.

Schäfers, Bernhard. 1996. Der Vereinigungsprozeß in sozialwissenschaftlichen Deutungsversuchen. In Soziologie und Gesellschaftsentwicklung. Aufsätze 1966-1996, Hrsg. Bernhard Schäfers, 181-192. Opladen: Leske \& Budrich.

Schelsky, Helmut. 1959. Ortsbestimmung der deutschen Soziologie. Düsseldorf: Diederichs.

Schelsky, Helmut. 1981. Rückblicke eines „Anti-Soziologen“. Opladen: Westdeutscher Verlag.

Scheuch, Erwin K. 2001. Soziologie in Köln. In Gute Gesellschaft? Verhandlungen des 30. Kongresses der Deutschen Gesellschaft für Soziologie in Köln 2000. Teil A, Hrsg. Jutta Allmendinger, 113-168. Opladen: Leske \& Budrich.

Schildt, Axel, und Detlef Siegfried. 2009. Deutsche Kulturgeschichte. Die Bundesrepublik von 1945 bis zur Gegenwart. München: Hanser.

Schimank, Uwe. 2000. Soziologische Gegenwartsdiagnosen - Zur Einführung. In Soziologische Gegenwartsdiagnosen I: Eine Bestandsaufnahme, Hrsg. Uwe Schimank und Ute Volkmann, 9-22. Opladen: Leske \& Budrich.

Schluchter, Wolfgang. 1996. Neubeginn durch Anpassung? Studien zum ostdeutschen Übergang. Frankfurt a. M.: Suhrkamp.

Schmid, Michael. 2004. Rationales Handeln und soziale Prozesse. Wiesbaden: VS Verlag für Sozialwissenschaften.

Schnitzler, Sonja. 2016. Die Deutsche Gesellschaft für Soziologie zur Zeit des Nationalsozialismus. In Handbuch Geschichte der deutschsprachigen Soziologie, Bd. 1, Hrsg. Stephan Moebius und Andrea Ploder. Wiesbaden: Springer VS (i.E.).

Schultheis, Franz, und Kristina Schulz. Hrsg. 2005. Gesellschaft mit begrenzter Haftung: Zumutungen und Leiden im deutschen Alltag. Konstanz: UVK.

Schwartz, Michael. 1995. Sozialistische Eugenik. Eugenische Sozialtechnologien in Debatten und Politik der deutschen Sozialdemokratie 1890-1933. Berlin: Dietz Verlag.

Shils, Edward. 1975. Geschichte der Soziologie: Tradition, Ökologie und Institutionalisierung. In Soziologie - autobiographisch, Hrsg. Talcott Parsons, Edward Shils und Paul Felix Lazarsfeld, 69-146. Stuttgart: Enke.

Sieg, Alexander. 2002. Konditionen und Strukturen internationaler Rezeption von Fachwissen in der frühen deutschen und amerikanischen akademischen Soziologie. Diss. Berlin. URL: http://webdoc. sub.gwdg.de/ebook/diss/2003/fu-berlin/2003/56/, hier: http:/webdoc.sub.gwdg.de/ebook/diss/2003/ fu-berlin/2003/56/teil3kap2.pdf (Zugegriffen: 14.07.2016). 
Sloderdijk, Peter. 2009. Die Revolution der gebenden Hand. In Frankfurter Allgemeine Zeitung, 13. Juni 2009, online: http://www.faz.net/aktuell/feuilleton/debatten/kapitalismus/die-zukunft-deskapitalismus-8-die-revolution-der-gebenden-hand-1812362.html (Zugegriffen:: 11.10.2016).

Srubar, Ilja. Hrsg. 1988. Exil, Wissenschaft, Identität. Die Emigration deutscher Sozialwissenschaftler 1933-1945. Frankfurt a. M.: Suhrkamp.

Srubar, Ilja. 2010. Der Streit um die Wissenssoziologie. In Soziologische Kontroversen. Eine andere Geschichte der Wissenschaft vom Sozialen, Hrsg. Georg Kneer und Stephan Moebius, 46-78. Berlin: Suhrkamp.

Stölting, Erhard. 1984. Kontinuitäten und Brüche in der deutschen Soziologie 1933/34. Soziale Welt 35:48-59.

Stölting, Erhard. 1986. Akademische Soziologie in der Weimarer Republik. Berlin: Duncker \& Humblot.

Stölting, Erhard. 2006. Die Soziologie in den hochschulpolitischen Konflikten der Weimarer Republik. In Soziologie an deutschen Universitäten: Gestern- heute -morgen, Hrsg. Bettina Franke und Kurt Hammerich, 9-30. Wiesbaden: VS Verlag für Sozialwissenschaften.

Streeck, Wolfgang. 2008. Korporatismus. In Handbuch der Politischen Philosophie und Sozialphilosophie, Bd. 1, Hrsg. Stefan Gosepath, Wilfried Hinsch und Beate Rössler, 655-658. Berlin: de Gruyter.

Tent, James F. 1998. Academic proconsul. Havard sociologist Edward Y. Hartshorne and the reopneing of German universities, 1945-1946. His personal account. Trier: WVT.

Thierse, Wolfgang. 1994. Fremde im eigenen Land. Nach der Einheit die Entfremdung? In Perspektiven für Deutschland, Hrsg. Warnfried Dettling, 51-61. München: Knaur.

Tyrell, Hartmann. 1986. Helmut Schelskys Familiensoziologie. In Helmut Schelsky - ein Soziologe in der Bundesrepublik, Hrsg. Horst Baier, 45-56. Stuttgart: Enke.

Volkmann, Ute. 2015. Soziologische Zeitdiagnostik. Eine wissenssoziologische Ortsbestimmung. Soziologie. Forum der Deutschen Gesellschaft für Soziologie 44:139-152.

Weyer, Johannes. 1986. Der „Bürgerkrieg in der Soziologie“. Die westdeutsche Soziologie zwischen Amerikanisierung und Restauration. In Ordnung und Theorie. Beiträge zur Geschichte der Soziologie in Deutschland, Hrsg. Sven Papcke, 280-304. Darmstadt: WBG.

Wielgohs, Jan, und Marianne Schulz. 1993. Von der „friedlichen Revolution“ in die politische Normalität. Entwicklungsprobleme der ostdeutschen Bürgerbewegung. In Der Zusammenbruch der DDR. Soziologische Analysen, Hrsg. Hans Joas und Martin Kohli, 222-245. Frankfurt a. M.: Suhrkamp.

Wiese, Leopold von. 1921. Kölner Vierteljahrshefte für Sozialwissenschaften, Reihe A: Soziologische Hefte.

Wiese, Leopold von. 1933/34. Nach zwölf Jahren. Kölner Vierteljahreshefte für Soziologie 12 (3/4): 225-229.

Wiese, Leopold von. 1948a. Die gegenwärtige Situation, soziologisch betrachtet. In Verhandlungen des Achten Deutschen Soziologentages vom 19. bis 21. September 1946 in Frankfurt am Main. Vorträge und Diskussionen in der Hauptversammlung und in den Sitzungen der Untergruppen, Hrsg. Deutsche Gesellschaft für Soziologie, 20-40. Tübingen: Mohr.

Wiese, Leopold von. 1948b. Erstes Vorwort. In Verhandlungen des Achten Deutschen Soziologentages vom 19. bis 21. September 1946 in Frankfurt am Main. Vorträge und Diskussionen in der Hauptversammlung und in den Sitzungen der Untergruppen, Hrsg. Deutsche Gesellschaft für Soziologie, 1-6. Tübingen: Mohr.

Wiese, Leopold von. 1957. Erinnerungen. Opladen: Westdeutscher Verlag.

Wiese, Leopold von. 1959. Die Deutsche Gesellschaft für Soziologie. Persönliche Eindrücke in den ersten fünfzig Jahren (1909-1959). In 50 Jahre Deutsche Gesellschaft für Soziologie, Kölner Zeitschrift für Soziologie und Sozialpsychologie 1, Hrsg. König, René, 11-20. Stuttgart: Enke.

Windolf, Paul. Hrsg. 2005. Finanzmarkt-Kapitalismus. Analysen zum Wandel von Produktionsregimen, Sonderheft 45/2005 der Kölner Zeitschrift für Soziologie und Sozialpsychologie. Wiesbaden: VS Verlag für Sozialwissenschaften.

Wöhrle, Patrick. 2015. Zur Aktualität von Helmut Schelsky. Einleitung in sein Werk. Wiesbaden: Springer VS.

Wolfrum, Edgar. 2013. Rot-Grün an der Macht. Deutschland 1998-2005. München: Beck.

Zapf, Wolfgang. 1991a. Modernisierung und Modernisierungstheorien. In Die Modernisierung moderner Gesellschaften: Verhandlungen des 25. Deutschen Soziologentages in Frankfurt am Main 1990, Hrsg. Wolfgang Zapf, 23-39. Frankfurt a. M.: Campus.

Zapf, Wolfgang. 1991b. Die DDR 1989/1990 - Zusammenbruch einer Sozialstruktur? Berliner Journal für Soziologie 1:147-155.

Zürcher, Markus. 1995. Unterbrochene Tradition. Die Anfänge der Soziologie in der Schweiz. Zürich: Chronos. 
Zürcher, Markus. 2016. Anfänge der Soziologie in der Schweiz. In Geschichte der deutschsprachigen Soziologie, Bd. 1, Hrsg. Stephan Moebius und Andrea Ploder. Doi: 10.1007/978-3-658-07998-7_4-1 (Zugegriffen: 01.07.2016).

Stephan Moebius Prof. Dr. für Soziologische Theorie und Ideengeschichte, Leiter des Instituts für Soziologie der Karl-Franzens-Universität Graz. Forschungsschwerpunkte: Geschichte der deutschen Soziologie seit 1945; Letzte Veröffentlichungen: René König und die „Kölner Schule“. Eine soziologiegeschichtliche Annäherung. Wiesbaden 2015; Methodologie soziologischer Ideengeschichte. In: Handbuch Geschichte der deutschsprachigen Soziologie, Teilband 2. Wiesbaden 2017 (hrsg. zus. mit A. Ploder); Schulen, Akteure und regionale Zentren in der frühen bundesrepublikansichen Soziologie. In: Handbuch Geschichte der deutschsprachigen Soziologie, Teilband 1, Wiesbaden 2017 (hrsg. zus. m. A. Ploder); Soziologische Kontroversen in der deutschsprachigen Soziologie nach 1945. In: Handbuch Geschichte der deutschsprachigen Soziologie, Teilband 1, Wiesbaden 2017 (hrsg. zus. m. A. Ploder). 